\title{
Carbon Nanomaterials Interfacing with Neurons: An In vivo Perspective
}

\author{
Michele Baldrighi ${ }^{1}$, Massimo Trusel ${ }^{2}$, Raffaella Tonini ${ }^{2}$ and Silvia Giordani ${ }^{\text {* }}$ \\ ${ }^{1}$ Nano Carbon Materials Laboratory, Istituto Italiano di Tecnologia, Genova, Italy, ${ }^{2}$ Neuroscience and Brain Technology, \\ Istituto Italiano di Tecnologia, Genova, Italy
}

Developing new tools that outperform current state of the art technologies for imaging, drug delivery or electrical sensing in neuronal tissues is one of the great challenges in neurosciences. Investigations into the potential use of carbon nanomaterials for such applications started about two decades ago. Since then, numerous in vitro studies have examined interactions between these nanomaterials and neurons, either by evaluating their compatibility, as vectors for drug delivery, or for their potential use in electric activity sensing and manipulation. The results obtained indicate that carbon nanomaterials may be suitable for medical therapies. However, a relatively small number of in vivo studies have been carried out to date. In order to facilitate the transformation of carbon nanomaterial into practical neurobiomedical applications, it is essential to identify and highlight in the existing literature the strengths and weakness that different carbon nanomaterials have displayed when probed in vivo. Unfortunately the current literature is sometimes sparse and confusing. To offer a clearer picture of the in vivo studies on carbon nanomaterials in the central nervous system, we provide a systematic and critical review. Hereby we identify properties and behavior of carbon nanomaterials in vivo inside the neural tissues, and we examine key achievements and potentially problematic toxicological issues.

Keywords: carbon nanomaterials, in vivo studies, central nervous system, neuroprotection, drug delivery, imaging International School for Advanced Studies \& University of Trieste, Italy

*Correspondence: Silvia Giordani silvia.giordani@iit.it

Specialty section: This article was submitted to

Neural Technology, a section of the journal Frontiers in Neuroscience

Received: 27 December 2015 Accepted: 20 May 2016

Published: 09 June 2016

Citation:

\section{INTRODUCTION}

In the last two decades carbon nanomaterials (CNMs) experienced an exponential increase in the number of application fields where they demonstrate excellent performances. As for many other nanomaterials, the interest from the scientific community on carbon nanomaterials is devoted to exploring their potential use in biomedicine in addition to engineering their application for goods manufacturing. Their nano-size enables to exploit unconventional interaction pathways with living systems (Freitas, 2005), for example allowing the delivery in the brain tissues of molecules that are usually rejected by the blood-brain barrier (BBB).

Carbon nanomaterials exhibit big diversity in structure, morphology, physical properties and chemical reactivity. Carbon nanotubes (CNTs), carbon nanohorns (CNHs), nanodiamonds (NDs), fullerenes, carbon nano-onions (CNOs), graphene and derivatives have emerged as promising classes of nanomaterials for imaging, diagnostic and therapeutic applications. Their atomic composition, i.e., carbon, has a much lower inherent toxic potential than the atomic species used in the manufacturing of other kinds of nanoparticles (usually transition metals or silica; Sohaebuddin et al., 2010; Sharifi et al., 2012). In addition, their peculiar physical properties and shapes display different interaction behaviors within cells and tissues, and their properties can 
be tailored by covalent and non-covalent functionalization that allows to modify their surface charge and to introduce fluorescent tags (Bartelmess et al., 2015a), cell-specific and disease-specific targeting molecules (Fabbro C. et al., 2012), Magnetic Resonance Imaging (MRI) contrast agents (Hahn et al., 2011), as well as drugs and nucleic acids (Bianco et al., 2005a; Cheung et al., 2010). Finally, the synthesis of raw carbon nanomaterials usually relies on very cheap sources and involves few synthetic steps, making cost-effective their large scale production (De Volder et al., 2013).

Carbon nanotubes are the most studied carbon nanomaterials for biomedical applications (Bianco et al., 2005b; Liu Z. et al., 2009; Gong et al., 2013; Lamberti et al., 2015). In the last few years, however, the scientific community has been showing a growing interest in graphene and graphene oxide (Zhang Y. et al., 2012; Zhang H. et al., 2013; Yang et al., 2013a), nanodiamonds (Mochalin et al., 2011; Perevedentseva et al., 2013) and carbon dots (Shen et al., 2012; Luo et al., 2013). On the opposite fullerenes, which attracted a lot of attention in the past, are now experiencing a gradual loss of interest due to concerns regarding toxicity (Zhu et al., 2006; Kolosnjaj et al., 2007; Partha and Conyers, 2009; Matija et al., 2013). Carbon nano-onions also are attracting attention for their possible biomedical application (Ghosh et al., 2011; Sonkar et al., 2012; Yang M. et al., 2013; Bartelmess et al., 2014, 2015b,c; Giordani et al., 2014; Frasconi et al., 2015a,b). Notably, it has been demonstrated either in vitro and in vivo that carbon nanomaterials can be efficiently degraded by means of enzymatic catalytic oxidation processes that are occurring either in plants, prokaryotes and eukaryotes (Kotchey et al., 2012, 2013; Bussy et al., 2015; Elgrabli et al., 2015; Sureshbabu et al., 2015) thus helping to dispel doubts regarding possible bioaccumulation hazards. A number of studies highlight high toxicity of carbon nanomaterials for fishes and amphibians (Zhu et al., 2006; Smith et al., 2007; Mouchet et al., 2008; Li J. et al., 2015). However, such non-specific and important toxicity is not observed in mammals, and studies regarding these species are not considered in this review.

Several efforts from the scientific community are devoted to investigate how carbon nanomaterials functionally interface with the central nervous system (CNS). There are great expectations on these materials since they show excellent compatibility with

\footnotetext{
Abbreviations: ACh, acetylcholine; AD, Alzheimer's disease; FALS, familial amyotrophic lateral sclerosis; $\mathrm{BBB}$, blood-brain barrier; $\mathrm{CD}$, carbon dots; $\mathrm{CED}$, convection-enhanced delivery; CNFs, carbon nanofibers; CNHs, carbon nanohorns; CNMs, carbon nanomaterials; CNOs, carbon nano-onions; CNS, central nervous system; CNTs, carbon nanotubes; CVD, chemical vapor deposition; DEX, dextran; DOX, doxorubicin; DTPA, diethylene triamine pentaacetic acid; EPI, epirubicin; FUS, focused ultrasounds; GFAP, glial fibrillary acidic protein; GI, gastrointestinal; GlcNF, glucosamine conjugate fullerenol; GO, graphene oxide; HIV, human immunodeficiency virus; i.c.v., intracerebrovascular; i.p., intraperitoneal; i.v., intravenous; LFUS, low intensity focused ultrasound; MCAO, middle cerebral arteria occlusion; MPTP, 1-methyl-4phenyl-1,2,3,6-tetrahydropyridine; MRI, magnetic resonance imaging; MWCNTs, multi-wall carbon nanotubes; NDs, nanodiamonds; NK, natural killer; NO, nitric oxide; PCBM, phenyl-C61-butyric acid methyl ester; PD, Parkinson's disease; PEG, polyethylenglycol; PERF, perfenidone; PF-127, Pluronic F127; PVP, polyvinylpyrrolidone; QDs, quantum dots; RDX, cyclotrimethylenetrinitramine; ROS, reactive oxygen species; SCI, spinal cord injury; siRNA, small interfering RNA; SWCNHs, single-wall carbon nanohorns; SWCNTs, single-wall carbon nanotubes; TLR9, toll-like receptor 9; Tf, transferrin; TNT, 2,4,6-trinitrotoluene.
}

neuronal cells in vitro (Mattson et al., 2000; Webster et al., 2004; Li et al., 2011; Hopper et al., 2014), which makes them good candidates for the development of innovative diagnostic systems and therapeutic agents for brain pathologies such as neuronal or glial tumors. Moreover, the peculiar physical features of some of them, like the very high mechanical strength and the electrical conductivity, combined with their very low dimensions which provide an intimate contact with cells, enable a possible application both as support materials for neuroregeneration, e.g., after spinal cord injuries (Roman et al., 2011), as well as interface materials for high-efficiency recording and stimulation of the neuronal activity. Despite carbon nanomaterials are extensively probed for a number of biomedical applications using in vivo models (Yang K. et al., 2010; Gong et al., 2013; Perevedentseva et al., 2013; Hong et al., 2015), the number of studies dedicated to the CNS is substantially lower. It should be noted that in most cases the results are of great interest and undoubtedly depict a great potential for these materials.

In this review we focus our attention on the in vivo studies in the CNS in order to provide a comprehensive view of past and ongoing research in this field, highlighting the goals achieved, the interaction with neural tissues and the toxicity.

\section{CARBON NANOTUBES}

Carbon Nanotubes (CNTs) (Iijima, 1991) are the mostknown and widest studied carbon nanomaterials. Their mechanical, thermal and electrical properties have been extensively investigated (Mintmire and White, 1995; Ruoff and Lorents, 1995; Salvetat et al., 1999; Odom et al., 2000; Dai, 2002; Cao et al., 2003; Popov, 2004), leading to their successful application in several commercial and prototype products (De Volder et al., 2013). From the structural point of view, CNTs consist of continuous rolled-up graphitic foils. They can be either single-walled (SWCNTs), if consisting of a single graphitic tube, or multi-walled (MWCNTs), if more concentric tubes are present. Their diameter ranges from 0.7 to $5 \mathrm{~nm}$ for SWCNTs and from 2 to $>30 \mathrm{~nm}$ for MWCNTs, and their length can vary from a few hundreds of $\mathrm{nm}$ to several hundreds of microns (Figure 1). Although different fabrication methods are possible, chemical vapor deposition (CVD) using hydrocarbons as feed material and metal nanoparticles as catalyst is the most used (Cassell et al., 1999; Andrews et al., 2002). Several chemical reactions have been developed in order to modify their surface properties and to introduce functional molecules important for biological research (Tasis et al., 2006; Battigelli et al., 2013a).

The use of CNTs for the development of new diagnostic and therapeutic agents is of primary interest in biomedical research. Carbon nanotubes are successfully applied in sensing, imaging, drug delivery, and also nucleic acid delivery applications both in single cells and in vivo (Kateb et al., 2007; Ladeira et al., 2010; Wu et al., 2010; Al-Jamal et al., 2011; Liu Z. et al., 2011; Bates and Kostarelos, 2013; Battigelli et al., 2013a,b; Hong et al., 2015).

Toxicity of carbon nanotubes is a matter of debate: a number of studies highlight toxic effects in cells upon CNTs exposure (Muller et al., 2005; Magrez et al., 2006; Smith et al., 2007; 
(A)
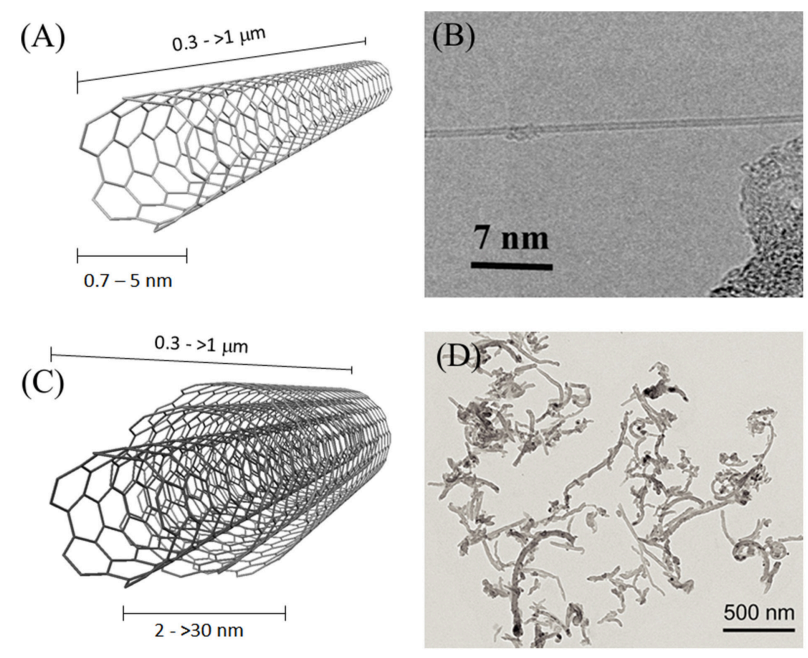

FIGURE 1 | Schematic representation of (A) SWCNTS and (C) MWCNTs. (B) HRTEM micrograph of a single SWCNT; reprinted with permission from Zhang Y. et al. (2010), Copyright (2010) American Chemical Society. (D) HRTEM micrograph of MWCNTs, functionalized with N-methylpyrrolidine groups to improve their solubility in organic solvents; adapted from Cellot et al. (2011), copyright Society for Neurosciences (2011).

Mouchet et al., 2008; Sharifi et al., 2012; Li J. et al., 2015). It should be noted, however, that a great contribution to these adverse effects could be led back to $\mathrm{Fe}, \mathrm{Ni}, \mathrm{Co}$, and $\mathrm{Y}$ nanoparticles deriving from the CNTs synthesis, that are still present in variable amounts in raw CNTs samples. The careful removal of metal contaminants as well as chemical functionalization in fact lead to a drastic reduction of the nanomaterial toxicity (Pulskamp et al., 2007; Movia et al., 2011; Movia and Giordani, 2012). A further source of concerns is their similar behavior to that of asbestos fibers: their tendency to aggregate in bundles (especially for unfunctionalized CNTs) can lead to the occurrence of important inflammatory responses (Poland et al., 2008), which can be alleviated by improving the nanomaterial dispersibility thanks to its covalent or noncovalent functionalization with polar moieties (Ali-Boucetta et al., 2013). In experiments involving neuronal cells, which are commonly considered particularly sensitive to toxicants and inflammation, high purity and functionalized carbon nanotubes seldom show toxicity (Bardi et al., 2009; Gaillard et al., 2009; Vittorio et al., 2009; Yang Z. et al., 2010; Zhang Y. et al., 2010, 2011; Bussy et al., 2015). Finally, it has been discovered that CNTs can be enzymatically degraded by peroxidases (Kotchey et al., 2012, 2013) in macrophages (Kagan et al., 2014), eosinophils (Andón et al., 2013), neutrophyls (Bhattacharya et al., 2014), and microglia (Bussy et al., 2016), as well as in the extracellular space (Farrera et al., 2014), thus mitigating the concerns regarding possible toxic effects due to their accumulation inside the body.

CNTs are permissive substrates for the adhesion and growth of primary neurons (Mattson et al., 2000; Hu et al., 2004; Gabay et al., 2005; Gheith et al., 2005; Lovat et al., 2005; Dubin et al., 2008; Gaillard et al., 2009; Kam et al., 2009; Tran et al., 2009; Jin et al., 2011; Park et al., 2011a). They also promote stem cells differentiation into neurons (Chao et al., 2009; Park et al., 2011a), action potential appearance in immature neurons (Fabbro et al., 2013) and they stimulate the propagation of dendritic backcurrents in isolated neurons (Cellot et al., 2009). Collectively, this evidence suggests their possible use for the therapy of neurodegenerative pathologies and spinal cord injuries. Moreover, CNTs are applied to record and stimulate neural activity in single neurons, artificial ganglia and spinal cord sections (Gheith et al., 2006; Mazzatenta et al., 2007; Kam et al., 2009; Shein et al., 2009; Shoval, 2009; Cellot et al., 2011; Fabbro A. et al., 2012; David-Pur et al., 2014). Microelectrodes coated with CNTs show enhanced sensitivity in neuronal activity recordings compared to state of the art devices (Keefer et al., 2008; Jan et al., 2009; Luo et al., 2011). Finally, CNTs are also able to deliver functional molecules inside neurons (Kateb et al., 2007; Wang C.-H. et al., 2009; Cellot et al., 2010; Ren et al., 2012).

CNTs show in general good compatibility in vivo with neuronal tissues. Intravenous (i.v.) administration of ${ }^{13} \mathrm{C}$ enriched SWCNTs in mice (Yang et al., 2007) demonstrates that these nanomaterials $(10-30 \mathrm{~nm} \times 2-3 \mu \mathrm{m}$ bundles) are able to cross the $\mathrm{BBB}$ and accumulate inside the brain tissues, although to a little extent. Furthermore, this study indicates that SWCNTs do not show acute toxicity despite their accumulation in several organs (especially liver, lungs, and spleen) and their low clearance. However, it has to be underlined that the long persistency of SWCNTs in lungs and in the liver can provide moderate toxicity in these organs (Yang et al., 2008).

A very recent report indicates that high doses of PEG-SWCNTs (1-10 $\mu \mathrm{m}$ bundles) display toxicity when stereotactically injected in rat hippocampus (Dal Bosco et al., 2015). Apparently PEG-SWCNTs are impairing contextual fear memory after long-term exposure at 0.5 and $1 \mathrm{mg} / \mathrm{mL}$ concentrations because of the oxidative stress generated by the nanomaterial. Although this study highlights how an eventual accumulation of CNTs inside the brain tissues can potentially lead to toxic effects, it is extremely unlikely that such high concentrations can be reached in localized regions of the CNS, unless local administration is used. Moreover, no explanation can be found to the evidence that higher concentrations of PEG-SWCNTs $(2.1 \mathrm{mg} / \mathrm{mL})$ do not cause oxidative stress and in general toxicity in the hippocampal tissues.

MWCNTs display in general a high biocompatibility in vivo with neural tissues: direct injection of a suspension of MWCNTs $(10-30 \mathrm{~nm} \times 2 \mu \mathrm{m})$ coated with the nonionic surfactant Pluronic F127 (PF-127) in mice visual cortex (Bardi et al., 2009) results in no substantial morphological differences observed in brain tissues comparing to a control injection, also in terms of injection lesion volume. Later timepoint analysis too revealed no sign of damage to the surrounding tissues apart from the expected gliosis engulfing the nanotubes (Figure 2). MWCNTs are also able to cross the BBB: $\left[{ }^{111} \mathrm{In}\right]$-DTPA-MWCNTs $(20 \mathrm{~nm} \times 0.5$ $\mu \mathrm{m}$ ) administered in vivo by tail vein injection (Kafa et al., 2015) display a maximum brain accumulation of $1.1 \%$ of injected dose per gram of tissue $5 \mathrm{~min}$ after the injection, followed by a gradual slow excretion. Micropinocytosis from the perivascular epithelial cells seems in this case to be the main internalization mechanism and therefore transcellular uptake is hypothesized as the primary 


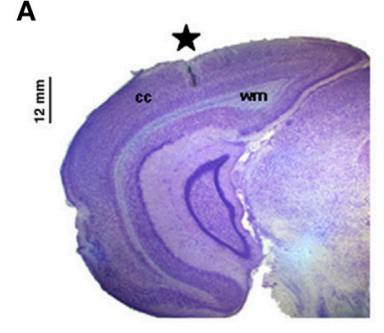

B

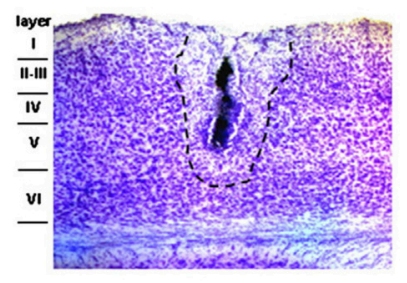

C

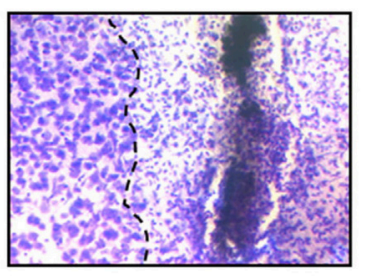

18 days

D

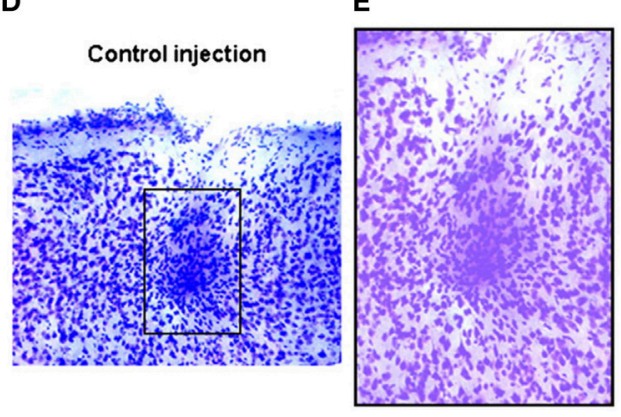

$\mathbf{F}$

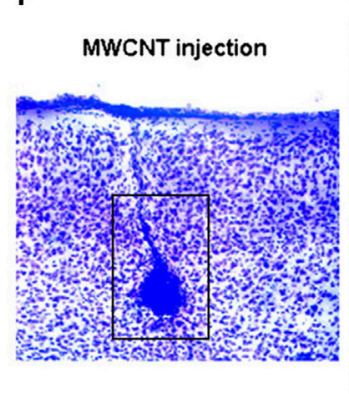

G

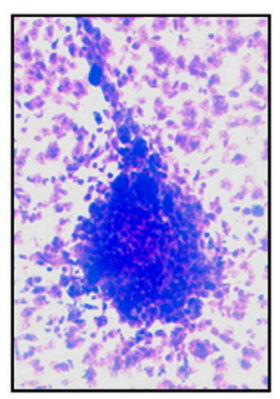

FIGURE 2 | Coronal brain slices showing short and long term effects of PF-127 coated MWCNTs intracortical injection. (A) Localization of the injection site (star); cc, cerebral cortex; wm, white matter. (B,C) Magnifications of the injection site 3 days after the injection: outside the lesion area (dashed line) cerebral tissues show normal neuronal density and tissue layering. (D,E) Control mice and (F,G) PF-127 coated MWCNTs injected mice brain slices 18 days after the injection: both the lesion sites present normal gliosis surrounding the injection site. Reprinted from Bardi et al. (2009), Copyright (2009), with permission from Elsevier.

mechanism for the BBB crossing (Kafa et al., 2015). As SWCNTs however, also MWCNTs tend to accumulate in the liver and the lungs where they can possibly produce toxicity in the long term.

Their morphological characteristics and their tendency to agglomerate are found to play a role in determining the nanomaterial's fate and inflammatory potential inside the brain: long ammonium MWCNTs (MWCNTs- $\mathrm{NH}_{3}^{+}, 20-30 \mathrm{~nm} \times$ 0.5-1 $\mu \mathrm{m}$ ) and short oxidized ammonium-MWCNTs (oxMWCNTs- $\left.\mathrm{NH}_{3}^{+}, 20-30 \mathrm{~nm} \times 0.2-0.3 \mu \mathrm{m}\right)$ display in fact remarkable differences after direct local injection in mice motor cortex (Bardi et al., 2013). Short ox-MWCNTs- $\mathrm{NH}_{3}^{+}$are confined in a very narrow area forming compact agglomerates and they can be found into the cytoplasm exclusively inside vesicles. Moreover, they show inflammatory potential, although it should be underlined that within 1 week the expression levels of the inflammatory cytokines return to normality. On the contrary, long MWCNTs- $\mathrm{NH}_{3}^{+}$distribute over a very large area, they are found into the cells both inside vesicles and free-floating in the cytoplasm and have low inflammatory potential. Remarkably, microglia is found to be able to degrade long MWCNTs- $\mathrm{NH}_{3}^{+}$ even at early time points (Nunes et al., 2012), providing partial to complete loss of their morphology. Also, it has been recently demonstrated that different CNTs functionalizations can vary the short-term kinetics of CNTs biodegradation by microglia (Bussy et al., 2016), however not providing relevant differences in the nanomaterial's long-term fate. These evidences indicate that the possible accumulation of CNTs, which may eventually produce toxic effects, can be efficiently prevented also in the brain thanks to the natural body defense mechanisms.

Besides the compatibility studies, CNTs have been also probed in vivo for their possible use as therapeutic agents, in particular as neuroprotectants against ischemic damages. In this context, CNTs covalent amino/ammonium derivatives and their further modifications display very promising results. SWCNTs amino derivatives (SWCNTs- $\mathrm{NH}_{2}, 4-10 \mathrm{~nm} \times 0.5-1.5 \mu \mathrm{m}$ ) are able to drastically reduce the brain damages induced by stroke when preventively administered in lateral ventricles (Lee H. J. et al., 2011): after surgical transitory middle cerebral arteria occlusion (MCAO), SWCNTs- $\mathrm{NH}_{2}$ treated rats display a much lower cerebral infarction volume with respect to untreated rats. Also apoptosis, inflammatory, neurogenesis and angiogenesis levels in SWCNTs- $\mathrm{NH}_{2}$ treated rats' brains indicate that the nanotubes are effective in reducing cell death and inflammatory response and in promoting neuroregeneration. Most impressively, a complete restoring of motor function can be achieved in rats 7 days after the ischemic insult (Figure 3). The therapeutic efficacy of CNTs against brain ischemic damages can be improved by using the nanomaterial in order to deliver neuroprotective siRNAs. Ammonium-MWCNTs (MWCNTs- $\mathrm{NH}_{3}^{+}, 20-30 \mathrm{~nm} \times 0.5-2$ $\mu \mathrm{m})$, are known in fact to be efficient siRNA delivery systems (Al-Jamal et al., 2010), and can be loaded with Caspase-3 siRNA (siCAS3), which is able to inhibit the expression of caspase- 3 , an 


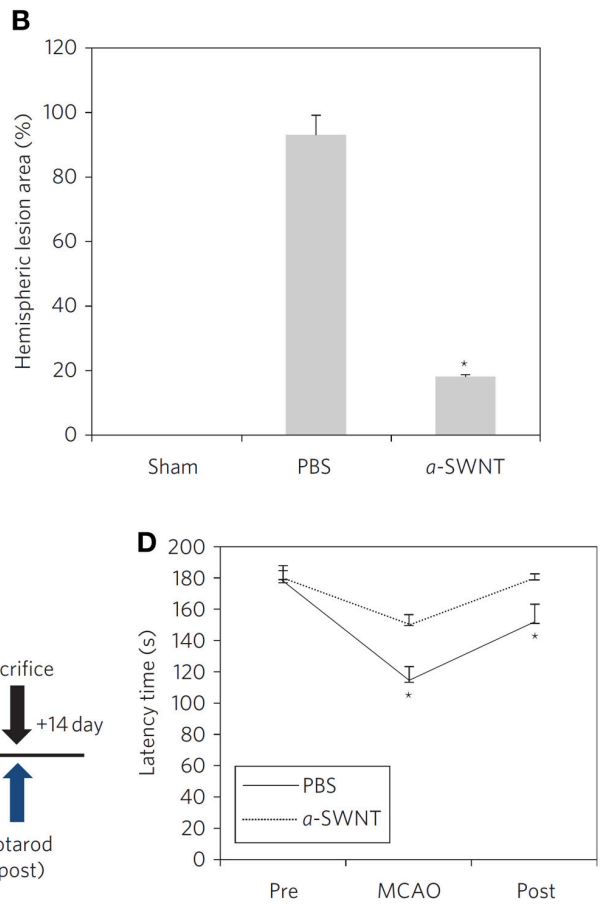

FIGURE 3 | Morphological and functional neuroprotective effects of the SWCNTs- $\mathrm{NH}_{2}$ pretreatment after ischemia-reperfusion. (A) Coronal brain sections (stained with tetrazolium chloride) of sham, PBS and SWCNTs-NH 2 (here called a-SWNT) treated mice, where white areas correspond to the infarcted regions after MCAO. (B) Quantification of the lesion in the brain sections showed in (A). (C) Schedule of motor functionality experiments. (D) Motor coordination results from Rotarod tests indicating complete recovery of motor coordination in SWCNTs- $\mathrm{NH}_{2}$ treated mice. Data reported as mean + s.e.m. ${ }^{*} P<0.001$ vs. pre-MCAO. Reprinted by permission from Mcmillan Publishers Ltd.: Nature Nanotechnology, Lee H. J. et al. (2011), Copyright (2011).

enzyme involved in apoptosis (Al-Jamal et al., 2011). Preventive administration of the nanomaterial inside rats brain parenchyma and its internalization by neurons within $48 \mathrm{~h}$ from the injection can therefore guarantee motor ability retention in rats after the induction of the ischemic insult. The combined neuroprotective effect of the nanomaterial and of the siRNA is particularly evident if considering that, after the ischemic insult, treated animals brains show apoptosis markers levels that are substantially similar to those of healthy animals. Unfortunately, similar results could not be obtained if the nanomaterial is administered after the stroke event.

Drug delivery into the brain is also one of the most desired biomedical applications of nanomaterials. By simply exploiting that unfunctionalized-but shortened-SWCNTs $(0.8-1.2 \mathrm{~nm} \times$ 50-300 $\mu \mathrm{m}$ ) administered through the gastrointestinal (GI) tract are able to cross the BBB and preferentially localize in neurons' lysosomes, it is possible to use these same SWCNTs to deliver Acetylcholine $(\mathrm{ACh})$ in Alzheimer's disease $(\mathrm{AD})$ model mice's brains through the GI tract. Once in the neuronal lysosomes, the acidic $\mathrm{pH}$ triggers the release of the drug from the AChSWCNTs to the neuron cytosol, providing the recovery of the mice's learning abilities (Yang Z. et al., 2010). Also the more bulky MWCNTs can show very interesting drug delivery abilities in the CNS, when opportunely functionalized in order to improve their dispersibility in aqueous media; moreover, the concomitant grafting of targeting biomolecules to the nanomaterial scaffold increases the specificity of the therapeutic action: doxorubicin (DOX) loaded oxidized MWCNTs (DOX-oMWCNTs, $10 \mathrm{~nm} \times$ 5-15 $\mu \mathrm{m})$ possessing a PEG unit and grafted with angiopep2 (ANG, a peptide targeting both the BBB and the LRP receptor expressed by glioma cells) demonstrate to be highly effective against glioma (Ren et al., 2012). Angiopep-2-targeted oMWCNTs are able to cross the $\mathrm{BBB}$ in higher quantity with respect to unfunctionalized or PEG-DOX functionalized MWCNTs, and to accumulate more selectively into the tumor mass. As result, mice treated with DOX-oMWCNTs-PEG-ANG show a $20 \%$ increase in survival compared to mice treated with the untargeted nanomaterial and by $42 \%$ with respect to mice treated with only DOX. DOX-oMWCNTs-PEG-ANG also display a little higher liver and spleen accumulation than DOX and DOX-oMWCNTs-PEG but lower kidney and lung accumulation, and a markedly reduced cardiac toxicity with respect to DOX, a characteristic which also represents a remarkable improvement.

Efficient delivery of therapeutic genetic material in the CNS can be also achieved thanks to SWCNTs. Alongside with the previously mentioned delivery of siRNA for ischemic damage reduction purposes, SWCNTs, and in particular PEGfunctionalized SWCNTs $(1-3 \mathrm{~nm} \times 0.2-0.4 \mu \mathrm{m})$, are able to deliver $C p G$ oligonucleotide ( $C p G$-CNTs), which has antitumor 
activity via activation of TLR9-mediated immune response, to the tumor-associated inflammatory cells in brain implanted glioma in mice (Zhao et al., 2011). The intracranial injection of $C p G$ CNTs provides the recruitment of Natural Killer (NK) and $\mathrm{CD}^{+}$cells and the development of immune response against the glioma cells, which results in tumor cells depletion and survival of $50-60 \%$ of treated mice, while no survival is observed when mice are treated with a single dose of non-conjugated $C p G$ oligonucleotide. Moreover, the adverse effects commonly associated with the standard $C p G$ antitumor therapy are not observed when using $C p G$-CNTs. Finally, the surviving treated mice develop immunity against glioma, therefore they undergo spontaneous remission of the tumor when this is re-injected into their brains.

CNTs were also probed for neuroregeneration applications in spinal cord injury (SCI) model rats. Post-injury administration of PEG-functionalized SWCNTs (PEG-SWCNTs) in the lesion site is found to promote axonal survival and repair, while delayed administration is able to achieve a dose-dependent reduction in the lesion volume in both gray and white matter, and an increase in the number of neuronal fibers in the lesion epicenter with a modest sprouting of corticospinal tract axons into this region (Roman et al., 2011). Neither alterations in reactive astrogliosis at the lesion site nor toxicity or neuropathic pain are present. As outcome, a dose-dependent moderate recovery of motility in treated rats is achieved.

Taking into account the studies above mentioned, carbon nanotubes emerge as extremely versatile materials for a number of useful applications in the CNS. Besides their singlewall or multi-wall nature, appropriately functionalized CNTs demonstrate to be good therapeutic agents against ischemic damage as well as excellent vectors for drug delivery in the CNS. Apparently MWCNTs are preferred to SWCNTs for delivery applications in the CNS, despite the fact that the latter display a higher specific surface area and therefore a higher loading capacity. Economical reasons may also play a role in the choice. CNTs show high biocompatibility with the brain tissues, contrary to the data reported in some cells studies and when administered in the lungs and in the GI tract. Important in this sense is that the CNTs used in these studies have been in general functionalized with highly polar moieties or they display structural characteristics that prevent their excessive aggregation in aqueous media, which can potentially give rise to immune response. Furthermore CNTs also demonstrate the ability to mitigate the toxicity of some drugs. In summary, we believe that CNTs have to be still considered cutting-edge nanomaterials for the therapy of CNS diseases.

\section{FULLERENES}

Fullerenes are defined molecular entities with a precise atomic composition and hollow spherical shape. Buckminsterfullerene, better known as $\mathrm{C}_{60}$ fullerene, is the first and the smallest stable fullerene isolated, and the most studied because of its relative ease of synthesis. It is obtained in relatively good yields from graphite using the arc-discharge technique, and purified from byproducts by solvent extraction followed by chromatography. In its structure the $60 \mathrm{sp}^{2}$-hybridized carbon atoms arrange to form a truncated icosahedron structure with a diameter of $0.7 \mathrm{~nm}$ (Figure 4). Several derivatives with hydrophilic (carboxyfullerenes) or lipophilic (PCBM) behavior were synthesized in order to increase the solubility in water and organic solvents.

Fullerenes are extensively studied in a number of applications such as organic photovoltaics (Brabec et al., 2010; Kirner et al., 2014), gas storage (Gadd et al., 1999), and molecular sensing (Baena et al., 2002; Sherigara et al., 2003). In the last 30 years fullerenes, alongside CNTs, were considered among the cuttingedge nanomaterials for biomedical applications: they were proposed as oxidative damage protecting agents, photosensitizers for photodynamic therapy of cancer, antiretroviral agents and as drugs and gene delivery vectors (Bakry et al., 2007; Tykhomyrov et al., 2008; Partha and Conyers, 2009; Chen et al., 2012; Matija et al., 2013). Fullerenes also were the pioneering carbon nanomaterials investigated in vivo for their potential applications in the therapy of brain diseases. However, the raising concerns of their toxicity has contributed to a reduction of the interest from the biomedical scientific community.

There are conflicting reports in literature regarding their toxicity. $\mathrm{C}_{60}$ has been documented for ex. both to induce reactive oxygen species (ROS) mediated toxicity and to provide efficient protection from ROS damage (Johnston et al., 2010). While it is generally accepted that pristine $\mathrm{C}_{60}$ displays just moderate toxicity (Tokuyama et al., 1993; Partha and Conyers, 2009; Aschberger et al., 2010; Johnston et al., 2010), its covalent and non-covalent derivatives can be instead very toxic (Trpkovic et al., 2012; Sergio et al., 2013). Furthermore, toxicity of pristine $\mathrm{C}_{60}$ is increased by the presence of surfactants or organic cosolvents (Johnston et al., 2010) and genotoxicity has been also reported (Dhawan et al., 2006). The high affinity of $\mathrm{C}_{60}$ for a number of chemical species along with its ability to permeate the biological membranes allows it to convey toxicants in the cells or to interfere with metabolic processes (Sergio et al., 2013). It

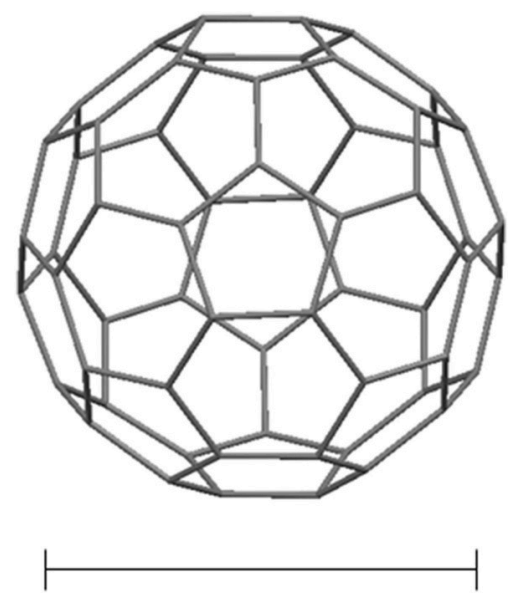

$0.7 \mathrm{~nm}$

FIGURE 4 | Schematic representation of $\mathrm{C}_{60}$ fullerene. 
should be noted however that toxicity evidences show a certain degree of variability that can be ascribed, in large part, to the very different experimental conditions and toxicity assays used.

Fullerenes are able to penetrate the neuronal cell membrane both in vitro and in vivo (Yamago et al., 1995; Dugan et al., 2001). They can accumulate in several tissues and, notably, they cross the BBB (Yamago et al., 1995). Despite the general indications of cytotoxicity, on neuronal cell cultures these compounds show neuroprotective and antioxidant effects (Dugan et al., 1996, 1997; Bisaglia et al., 2000).

In vivo, fullerenes are the first carbon nanomaterials found to distribute in the brain after systemic administration. Biodistribution studies using a ${ }^{14} \mathrm{C}$-radiolabeled carboxylated $\mathrm{C}_{60}$ derivative $\left({ }^{14} \mathrm{C}-\mathrm{C}_{60}\right)$ in rats after i.v. administration (Yamago et al., 1995) reveal that the nanomaterial rapidly spreads in several organs including brain, indicating that it is able to cross the BBB despite its high molecular weight $(995 \mathrm{Da})$. No toxic effects are observed after i.v. administration, while toxicity is observed after intraperitoneal injection. A possible explanation for this different behavior can be that the fullerene is able to induce a consistent inflammatory response only when it is administered in a confined site at high concentrations, while direct dilution in the bloodstream suppresses this accumulation-dependent toxicity. However, as the authors of this study point out, this nanomaterial has a high lipophilicity, which translates into slow excretion kinetics and accumulation in specific organs. This raises concerns about the possible occurrence of long-term toxicity or toxicity after chronic administration since the fullerene can reach with time toxic concentrations inside specific sites.

Alike CNTs, also fullerenes have been probed for their potential therapeutic activity in the CNS, especially for ROSscavenging purposes. The first and most studied fullerene demonstrating this property is carboxyfullerene, a $\mathrm{C}_{60}$ tris(malonic acid) water soluble derivative. Carboxyfullerene continuous i.p. administration by means of a mini-osmotic pump in transgenic mice carrying a human superoxide dismutase gene mutation related to familial amyotrophic lateral sclerosis (FALS) results in 15\% delay in the appearance of FALS symptoms, and 6\% increase of survival (Dugan et al., 1997). Carboxyfullerene is also able to protect nigrostriatal dopaminergic neurons against the oxidative stress generated by Iron(II) injection (Lin et al., 2001), used as a Parkinson's disease model: intracranial co-administration of the nanomaterial at low doses with Iron(II) into mice's substantia nigra is able to inhibit the induced ROS generation, keeping dopamine levels and dopaminergic response similar to basal values. Although the two nanomaterials are co-administered, it is unlikely that neuroprotection occurs thanks to metal sequestration or direct reduction of the metal ion operated by the fullerene, rather it is likely to act as free radical scavenger as demonstrated by EPR spectroscopy experiments (Dugan et al., 1997). Finally, in MCAO stroke model, intraventricular injection of high doses $(0.3 \mathrm{mg} / \mathrm{rat})$ of carboxyfullerene in rats brain 30 min prior to infarction is able to fully contrast the ischemia-generated ROS production, providing $83 \%$ reduction of the infarcted area (Lin et al., 2002). Nevertheless, in the latter case the authors report adverse effects such as writhing with stretching of the trunk in more than a third of the treated animals, with death occurring in the $60 \%$ of these cases. Administration of a lower (but still high) dose ( $0.1 \mathrm{mg} / \mathrm{rat}$ ) of the nanomaterial is free of adverse effects, but has limited efficacy. Systemic administration $(6 \mathrm{mg} / \mathrm{kg})$ through the tail vein also demonstrates to be nontoxic, however it has no effect on the infarction. These results indicate that the nanomaterial displays in general acute toxicity when employed locally in the CNS at high dosage, while it can be considered reasonably safe when it is locally administered at low doses or when systemic administration is employed.

Carboxyfullerene is proposed also as neuroprotective cerebral antiaging compound: daily administration of the nanomaterial to mice $(10 \mathrm{mg} / \mathrm{kg} / \mathrm{day})$ in drinking water is able to reduce the superoxide content in brain tissues to levels just above those of control young mice, implying that the nanomaterial is able to cross the BBB (Quick et al., 2008). An improved ability in memory behavioral tests and a $11 \%$ lifetime increase is also observed, suggesting a considerable antiaging effect exerted also to several other organs. A neuroprotective effect of carboxyfullerene after single systemic i.p. administration is evidenced also against $E$. Coli induced meningitis in mice (Tsao et al., 1999): although the nanomaterial has no direct antibacterial activity, preventive administration as well as post-infection treatment with carboxyfullerene $(6-40 \mathrm{mg} / \mathrm{kg}$, administered 3 times every $24 \mathrm{~h}$ ) decreases brain inflammation by modulating the immune response and preventing the $\mathrm{BBB}$ leaking due to inflammation, thus delaying or partially preventing (up to $80 \%)$ mice death in a dose-dependent way and more effectively than corticosteroids. The high doses of nanomaterial injected do not cause any toxic effect in mice, thus strengthening the hypothesis that the systemic administration of this nanomaterial is particularly well tolerated.

Carboxyfullerene has been also tested for the treatment of Parkinson's disease (PD) in MPTP treated non-human primates models (Dugan et al., 2014). The nanomaterial is delivered 1 week after MPTP injection by continuous systemic administration (3 $\mathrm{mg} / \mathrm{kg} /$ day) using either intraperitoneal or subcutaneous osmotic pumps. Significant differences between the placebo group and animals receiving carboxyfullerene are found starting from 30 days after the beginning of the treatment, with treated animals showing motor ability improvements approaching normal values at the end of the experiment (Figure 5). This indicates that the continuous administration of carboxyfullerene is able to induce the recovery of dopaminergic neurotransmission even after the MPTP-induced neuronal death process has already begun. Moreover, despite the prolonged duration of the experiment and the continuous administration of the nanomaterial, only little evidences of toxicity are found. Results promote therefore a potential application of this nanomaterial for the cure of Parkinson's disease in humans.

Alongside carboxyfullerene, other $\mathrm{C}_{60}$ fullerene derivatives show neuroprotection capabilities: hexasulfobutylated- $\mathrm{C}_{60}$ $\left(\mathrm{FC}_{4} \mathrm{~S}\right)$, when administered i.v., is able to cross the BBB and prevent oxidative damage after MCAO stroke induction (Huang et al., 2001), providing up to $67 \%$ reduction of the infarcted brain volume after reperfusion. Intracellular oxidative stress is found to be perfectly normal, while interestingly the presence 

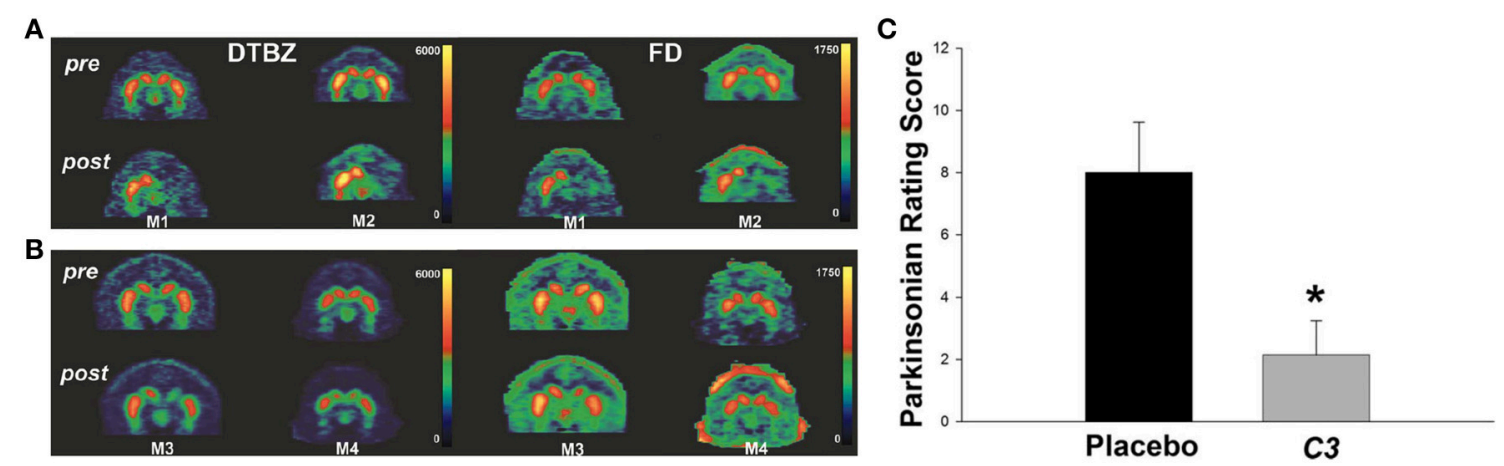

FIGURE 5 | (A,B) Positron emission tomography (PET) brain images using from two control primates (M1, M2) and two carboxyfullerene-treated primates (M3, M4) before MPTP injection (pre) and at the end of the treatment (post). $\left[{ }^{11} \mathrm{C}\right]$ dihydrotetrabenazine (DTBZ) and 6- $\left[{ }^{18} \mathrm{~F}\right]$ fluorodopa (FD) are used as probe for evaluating the nigrostriatal dopaminergic activity. As clearly visible placebo-treated animals are showing unsymmetrical distribution of tracers in the two hemispheres indicating partial loss of dopaminergic activity, while carboxyfullerene-treated animals are showing dopaminergic activity in both the hemispheres. (C) Parkinsonian rating score at the end of the treatment, indicating reduction of bradykinesia in carboxyfullerene (C3) treated animals with respect to animals receiving placebo. Data reported as mean + s.e.m. ${ }^{*} p=0.007$. Adapted from Dugan et al. (2014) with permission from John Wiley and Sons, Copyright (2014).

of increased levels of nitric oxide (NO) suggests that $\mathrm{FC}_{4} \mathrm{~S}$ may exert its neuroprotective action by activating specific cell signaling pathways. Furthermore, the authors report no adverse effect of the $\mathrm{FC}_{4} \mathrm{~S}$ administration. Thanks to the possibility to use i.v. administration and to the absence of adverse effects, this nanomaterial therefore is able to overcome the limitations displayed by carboxyfullerene (Lin et al., 2002) in the prevention of stroke-deriving ischemic damage. However, the prevention of brain infarction damages implies that the nanomaterial has to be chronically administered and therefore, prior to envisage possible uses of this nanomaterial in therapy, long-term toxicity studies must be performed. Among noncovalent derivatives of $\mathrm{C}_{60}$ fullerene, its adduct with poly(vinylpyrrolidone) $\left(\mathrm{C}_{60}-\mathrm{PVP}\right)$ displays neuroprotective capabilities: direct injection of the nanomaterial into rats hippocampus is able to protect memory consolidation mechanisms in rats when these are treated with cycloheximide, a protein synthesis inhibitor able to impair the memory consolidation processes (Podolski et al., 2005). Results seem to indicate that the ROS-scavenging ability of the fullerene adduct is the main responsible of preventing the neuronal apoptotic response to the drug. However, although no indications of adverse effects in the CNS are provided, the choice of local cerebral administration of this therapeutic agent raises concerns regarding the possible occurrence of toxicity.

Also unfunctionalized fullerene $\left(\mathrm{C}_{60}\right)$, in the form of water suspension of the pure nanomaterial as hydrated $\left(\mathrm{C}_{60} \mathrm{HyFn}\right)$, can be used for neuroprotection purposes. The administration of the nanomaterial in rats drinking water provides protection against neuronal damages deriving from chronic alcohol intake (Tykhomyrov et al., 2008). Analyses reveal that the nanomaterial is able to contrast the alcohol-induced depletion of glial fibrillary acidic protein (GFAP) in astrocytes as well as to preserve the expression of cytoskeletal proteins also in neurons and glia. No adverse effects due to the nanomaterial intake are observed. Additionally, $\mathrm{C}_{60} \mathrm{HyFn}$ demonstrates possible neuroprotective activity against Alzheimer disease (AD) neurodegeneration. In vitro, the nanomaterial is able in fact to interfere with the formation of $A \beta_{25-35}$ amyloid peptide fibrils structure, resulting in the accumulation of protofibrillar structures (Podolski et al., 2007). Rats injected with the amyloid peptide rapidly develop dementia, but when even low doses (maximum $5 \mu \mathrm{g} / \mathrm{rat}$ ) of $\mathrm{C}_{60} \mathrm{HyFn}$ are injected intracerebroventricular (i.c.v.) prior to the injection of the amyloid peptide, rats show normal cognitive abilities. Also, no evidence of nanomaterial toxicity is found (Podolski et al., 2007). A recent follow-up in this research indicates that hippocampal injection of $\mathrm{C}_{60} \mathrm{HyFn}$ is able to restore the cortical-hippocampal EEG interrelations disrupted by the injection in the same site of an $A \beta$ peptide to simulate AD (Vorobyov et al., 2015). As these reports demonstrate, unfunctionalized $\mathrm{C}_{60}$ fullerene show neuroprotective effects when administered both GI and locally in the CNS. Differently from carboxyfullerene however, unfunctionalized $\mathrm{C}_{60}$ does not show toxicity when administered directly in the brain tissues. Toxicological investigations on $\mathrm{C}_{60}$ fullerene suggest however a potential long-term toxicity of the nanomaterial (Yamada et al., 2008). Even though no severe acute toxicity is found, the i.c.v. injection of $\mathrm{C}_{60}$ is in fact found to interfere with neurotransmitter homeostasis in rats, causing behavioral changes in the animal. Interestingly, i.p. injection of $\mathrm{C}_{60}$ does not provide alterations in the cerebral neurotransmitters levels.

The last fullerene-derived nanomaterial that showed direct neuroprotective capabilities in vivo is fullerenol, i.e., polyhydroxylated $\mathrm{C}_{60}\left(\mathrm{C}_{60}-\mathrm{OH}\right)$. This derivative, which is already known from in vitro studies to display neuroprotective activity (Jin et al., 2000), and its glucosamine conjugate (GlcNF), designed in order to add anti-inflammatory activity to the nanomaterial, demonstrate to be very good neuroprotective agents against stroke insult (MCAO induced) after systemic administration in both normotensive (WKY) and hypertensive (SHR) rats (Fluri et al., 2015). The i.v. administration of 0.5 $\mathrm{mg} / \mathrm{kg}$ of $\mathrm{C}_{60}-\mathrm{OH}$ subsequent to reperfusion after MCAO results in $68 \%$ reduction and $26 \%$ reduction of the infarcted area volume 
(compared to control) in WKY and SHR rats respectively. The increase in $\mathrm{C}_{60}-\mathrm{OH}$ dosage does not provide sensible therapeutic improvements but results in the appearance of adverse effects and also of death, while the use of GlcN-F $(5 \mathrm{mg} / \mathrm{kg}$, equivalent to $0.5 \mathrm{mg} / \mathrm{kg}$ of $\mathrm{C}_{60}-\mathrm{OH}$ ), in SHR rats provides a greater reduction of the infarcted volume with respect to $\mathrm{C}_{60}-\mathrm{OH}$ without evidences of toxicity. However, it is found that the i.c.v. injection in rats of even small doses $(0.25 \mathrm{mg} / \mathrm{kg})$ of fullerenol produces important-although transitory-toxic effects on the monoamine neurotransmission and animal behavior (Yamada et al., 2010). This raises further and more alarming concerns about the nanomaterial safety, also regarding possible adverse effects that can arise in case of accumulation of the nanomaterial in the brain also after systemic administration. It should be underlined also that the results provided by $\mathrm{C}_{60}-\mathrm{OH}$ are in line with those of $\mathrm{FC}_{4} \mathrm{~S}$ (Huang et al., 2001). However, $\mathrm{FC}_{4} \mathrm{~S}$ seems to be effective at lower doses and it is not toxic. The effectiveness of GlcN-F in reducing the extent of infarcted brain volume in SHR rats is instead a very appreciable result since it is known that hypertension has a strong detrimental effect on the prognosis after stroke. It would be interesting then to examine the neuroprotective effect of $\mathrm{FC}_{4} \mathrm{~S}$ also in hypertensive rats in order to determine if it can be an equally effective and safer alternative to GlcN-F.

Although extensive researches have been conducted to address the intrinsic neuroprotective properties of fullerenes, there are very few reports regarding in vivo drug delivery and imaging applications within the CNS. Drug delivery has been probed using a $\mathrm{C}_{60}$ derivative having two enzymatically cleavable amantadine molecules, synthesized with the aim to create a new anti-parkinson agent that combined the pharmacological activity of amantadine with the neuroprotective activity of the fullerene (Nakazono et al., 2004): studies on Parkinson model rats demonstrate moderate activity of the fullerene drug when systemically administered at $10 \mathrm{mg} / \mathrm{kg}$ dose, while at higher doses the drug is ineffective probably because the nanodrug itself is inhibiting the enzyme deputed to the hydrolysis of the fullerene-amantadine bond. On the other hand brain tumors bioimaging using fullerenes derivatives was achieved by means of endohedral gadolinium- $\mathrm{C}_{82}$ fullerenol $\left(\mathrm{Gd} @ \mathrm{C}_{82}-\mathrm{OH}\right)$, where the paramagnetic $\mathrm{Gd}^{3+}$ cation is enclosed in the fullerene cage: after i.v. injection the nanomaterial can detect, by means of MRI, a C6 glioma tumor in rats brain (Shevtsov et al., 2014). The nanomaterial is accumulating inside the tumor and displays a higher detection efficiency than the standard contrast agents. Gd@ $\mathrm{C}_{82}-\mathrm{OH}$ is found to be nontoxic to the animals unless high concentrations $(\geq 12.5 \mathrm{mg} / \mathrm{kg}$ ) are used, while it is able to increase their survival time, implying also a potential antitumor activity.

In summary, fullerenes demonstrate a good potential as neuroprotective agents, while their use as drug delivery vectors or imaging agents, at least in the CNS, has been just marginally explored. Most importantly fullerenes, and in particular carboxyfullerene, display a not negligible toxic profile for the CNS that however can be drastically reduced when systemic administration is preferred to local acute administration. However, neuroprotective applications require chronic administration of the therapeutic agent, and long-term toxicological data on these nanomaterials are still scarce. Despite the very good results achieved, fullerenes represent the "past" of carbon nanomaterials research. This again is due to all the concerns related to their proven accumulation in several organs, their long persistency in the body and their-in generalunpredictable toxicity. With all these serious impairments, it is not easy to say if the risk-benefit ratio will still provide opportunities for the development of these nanomaterials for biomedical applications.

\section{GRAPHENE OXIDE AND DERIVED NANOMATERIALS}

Graphene is a thin layer of $\mathrm{sp}^{2}$-hybridized carbon atoms bonded together in a hexagonal honeycomb lattice. Its peculiar electronic properties and structure attract a lot of attention especially in the field of semiconductor technologies. Moreover, thanks to its high surface to volume ratio applications as high capacity storage material or as drug delivery system are also proposed. Graphene oxide (GO) is the most common derivative of graphene, made from the exfoliation of graphite by oxidation procedures. GO nanoparticles are usually $1 \mathrm{~nm}$ thick while their lateral size can span from few tens of $\mathrm{nm}$ to few $\mu \mathrm{m}$ (Figure 6). Albeit the synthetic procedure introduces defective sites that destroy the peculiar electronic properties of graphene, the presence of polarizable functionalities increases its stability as single free-standing layers and allows the direct further functionalization of the material. For these reasons, graphene oxide has been considered more suitable than graphene for biomedical applications. Moreover, depending on the size, composition, and degree of oxidation, GO can exhibit inherent and tunable optical absorption and emission properties, with emission wavelengths varying from NIR to blue light (Li J. L. et al., 2012; Zhu S. et al., 2012; Cao et al., 2013; Zhang X. et al., 2013).

Graphene and derived nanomaterials are intensively applied for biomedical purposes and show promising results in toxicants and tumor marker sensing, in vitro and in vivo imaging applications, drugs and nucleic acid delivery, tumor photothermal ablation, as well as stem cell differentiation substrates (Peng et al., 2010; Zhang L. et al., 2010; Huang, 2011; Kim et al., 2011; Robinson et al., 2011; Lee W. C. et al., 2011;
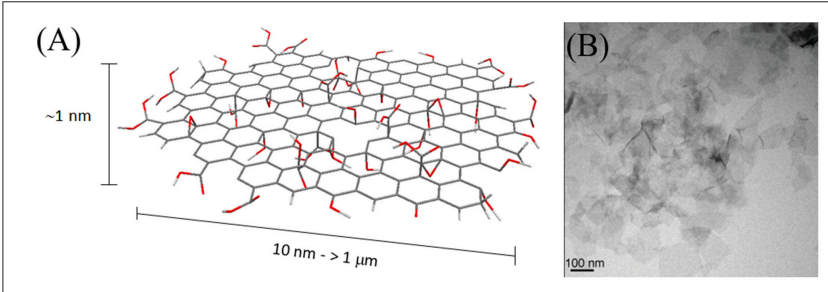

FIGURE 6 | (A) Schematic representation of GO. The nanomaterial surface and edges are characterized by the presence of carboxyls, carbonyls, alcohols, and epoxydes. (B) TEM micrograph of GO sheets; adapted from Zhang L. et al. (2010) with permission from John Wiley and Sons, Copyright (2010). 
Gollavelli and Ling, 2012; Hong et al., 2012; Li M. et al., 2012; Chung et al., 2013; Lalwani et al., 2013; Goenka et al., 2014). Their toxicity profile is, as for many other carbon nanomaterials, highly dependent on the functionalization, size and the aggregation behavior (Jastrzebska et al., 2012; Hu and Zhou, 2013; Wick et al., 2014). GO appears to be less toxic than pristine graphene, reduced graphene oxide or hydrogenated graphene, and the additional functionalization (with PEGs, aminogroups, etc.) contributes to a further reduction of the toxicity; graphene particles with few nm diameter are less toxic than larger particles; highly dispersible particles are less toxic than the aggregating ones. With respect to the other carbon nanomaterials, graphene and derivatives tend to accumulate in lungs and to reside in the organism for a longer time (Wang et al., 2010; Zhang Y. et al., 2010; Zhang X. et al., 2011; Yang et al., 2013b; Chng et al., 2014; Chwalibog et al., 2014; Kanakia et al., 2014; Seabra et al., 2014).

Recently, graphene and related materials are emerging as a convenient substrate and a powerful tool for neuronal growth and differentiation. Reports indicate that graphene is a permissive substrate for neuronal cells growth (Li et al., 2011, 2013; Park et al., 2011b; Movia and Giordani, 2012; Hong et al., 2014; Serrano et al., 2014; Tu et al., 2014; Fabbro et al., 2016) and the electrical conductivity of this material can be exploited to direct the elongation of neuronal processes in a controlled way (Li et al., 2011). Moreover, the electrical signals generated from neuronal cells can also be recorded by using graphene-based microelectrodes (Chen et al., 2011; Tang et al., 2013; Park et al., 2014). Surprisingly, it has also been shown that the physicochemical properties of this material favor the differentiation of neuronal stem cells preferentially toward the neurons fate (Park et al., 2011b; Wang et al., 2012; Akhavan and Ghaderi, 2013; Li et al., 2013). In these studies, toxicity assays show a good compatibility of graphene with neuronal cells (Chen et al., 2011; Li et al., 2011; Hong et al., 2014). In particular, reports show that graphene flakes (Zhang Y. et al., 2010) and graphenebased substrates (Hong et al., 2014; Song et al., 2014) may be even more compatible than other carbon-based nanostructures.

In vivo biodistribution studies reveal that $\mathrm{GO}$ has good potential for applications in the CNS: intravenous administration of radiolabeled GO ( ${ }^{188} \mathrm{Re}-\mathrm{GO}, 10-800 \mathrm{~nm}$ lateral size) in mice (Zhang X. et al., 2011) indicates that, despite most part of the nanomaterial is sequestrated by lungs, a small quantity (0.04\% of injected dose) is able to cross the BBB and migrate into the brain parenchyma. Similar results are obtained by administering i.v. GO $(0.3-1 \mu \mathrm{m}$ lateral size $)$ as suspension in PBS with the help of a surfactant. Remarkably, the presence of the surfactant allows to reduce lung accumulation, erythrocyte agglutination and macrophage activation (Qu et al., 2013). A further improvement has been made recently by noncovalently functionalizing GO with dextran (GO-DEX, 100-120 nm lateral size): after i.v. administration in mice, the nanomaterial is found to pass the BBB without exerting toxic effects in the brain and showing just minor effects in the other organs at the highest doses (>125 mg/Kg) (Kanakia et al., 2014). Interestingly, brain GO-DEX concentration is found 3 times higher 1 month after the injection with respect to $24 \mathrm{~h}$ after the injection, while it is almost completely cleared from all the other organs, thus indicating slow accumulation and long-term persistency of this nanomaterial in the CNS. If this can be considered a strength in view of applications as neuroprotective agents, on the other hand it raises concerns about possibilities of long-term toxicity, which however has not been explored yet.

Contrary to CNTs and fullerenes, GO and derivatives are not showing remarkable ROS scavenging capabilities in vitro, therefore no in vivo studies have been performed in order to assess their potential neuroprotective activity. Interestingly, GO and derivatives can be successfully applied for in vivo imaging purposes in the brain. PEG-functionalized GO (GOPEG, $40 \mathrm{~nm}$ lateral size), intracranially administered in mice, can be detected thanks to its fluorescence emission properties up to $300 \mu \mathrm{m}$ below the brain surface and its $3 \mathrm{D}$ distribution map in the brain parenchyma reconstructed (Figure 7) by using the two-photon imaging technique (Qian et al., 2012) in order to achieve high tissue penetration of the excitation light. Although preliminary, these results pave the way to the possible use of this nanomaterial for the imaging of brain cancerous lesions. This can be achieved firstly if GO nanoparticles are endowed of appropriate tumor-targeting functionalizations able to cause the selective accumulation of the nanomaterial inside the tumor mass. Furthermore, there is need to optimize the the nanomaterial characteristics (size, degree of oxidation), in order to shift its emission wavelength from the VIS spectral range that has poor tissue penetration, to the NIR, thus improving the imaging depth that is possible to achieve.

Although GO shows scarce tendency to reach high concentrations in cerebral tissues after systemic administration, its high specific surface area, which endows it of a high loading capacity, makes it a promising candidate also for drug delivery applications in the CNS. Strategies, such as low-invasive physical BBB opening techniques or chemical functionalization with efficient targeting moieties, can be used to overcome the low BBB permeability of GO. GO-PEG nanoparticles (120-150 $\mathrm{nm}$ lateral size) loaded with epirubicin (EPI), an anticancer drug, and decorated with magnetic $\mathrm{Fe}_{3} \mathrm{O}_{4}$ nanoparticles, can be used against U87 glioma xenographted in mice striatum (Yang H.-W. et al., 2013): after administration in the jugular vein, the nanodrug can be accumulated in the tumor mass by combining the use of low intensity focused ultrasound (LFUS), a physical BBB opening technique, and magnetic targeting. This results in a significant reduction of the tumor growth rate in the treated mice compared to control mice (Figure 8). It seems also that the use of GO and LFUS in combination is particularly effective due to the obtainment of local hyperthermia in the tumor. Magnetic GO-PEG-EPI nanoparticles are found to accumulate preferentially in the liver, from which they are completely cleared in $48 \mathrm{~h}$. No organ damages or weight loss, neither in vitro induction of immune response is found. The relatively rapid GO clearance and the absence of acute toxicity phenomena make this nanomaterial a suitable candidate for implementing the current brain tumor therapies.

Physical BBB opening techniques combined with GO can be also used to obtain simultaneous MRI imaging, drug delivery and miRNA delivery in the CNS. GO nanoparticles (140-150 nm lateral size) grafted with Gd-DTPA and poly(amidoamine) dendrimer, and loaded with EPI and Let-7, a tumor suppressor 


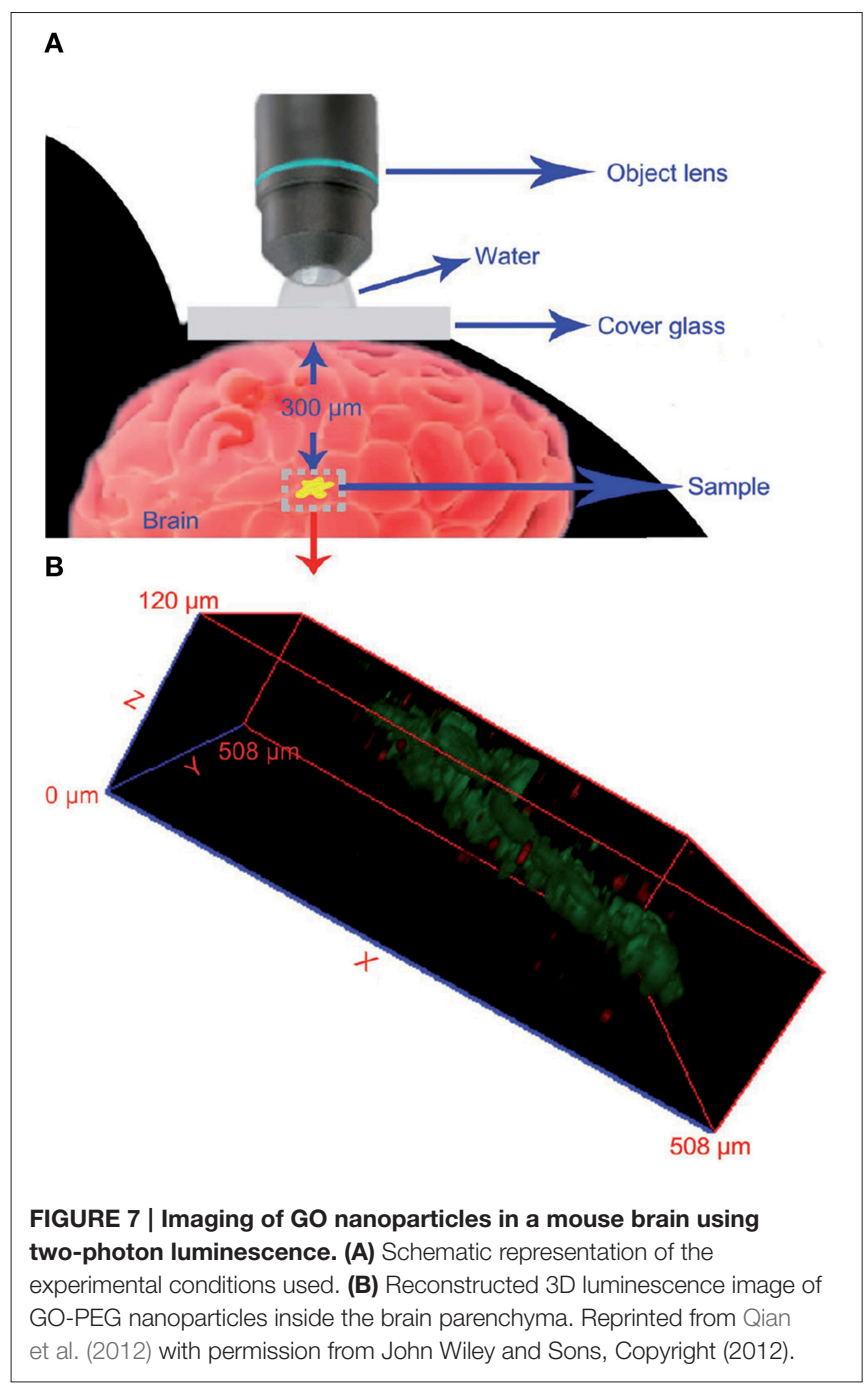

miRNA (Yang H.-W. et al., 2014) can be administered by tail vein injection in mice and allowed to cross the $\mathrm{BBB}$ thanks to the application of focused ultrasounds (FUS). The nanomaterial is able to provide very high contrast in MRI, which can be used in order to determine and quantify the distribution of the nanometric drug delivery system inside the brain tissues. Unfortunately, the study limits the demonstration of EPI internalization by glioma cells and miRNA transfection in their nuclei only to in vitro experiments. Although the results provided are very positive, it will be important to demonstrate in vivo the therapeutic efficacy of the nanodrug, and also to obtain pharmacokinetic and toxicological data.

Also chemical derivatization with suitable targeting moieties is able to provide the nanomaterial BBB crossing capabilities, making possible to pursue efficient drug delivery in the CNS. Transferrin (Tf) functionalized GO-PEG nanoparticles (Tf-PEGGO, 100-400 nm lateral size) are successful in delivering DOX in a brain tumor (Liu G. et al., 2013): after i.v. administration the nanoparticles are able to migrate from the bloodstream to a C6 glioma that has been implanted in rats striatum, where they are found significantly more concentrated than in the rest

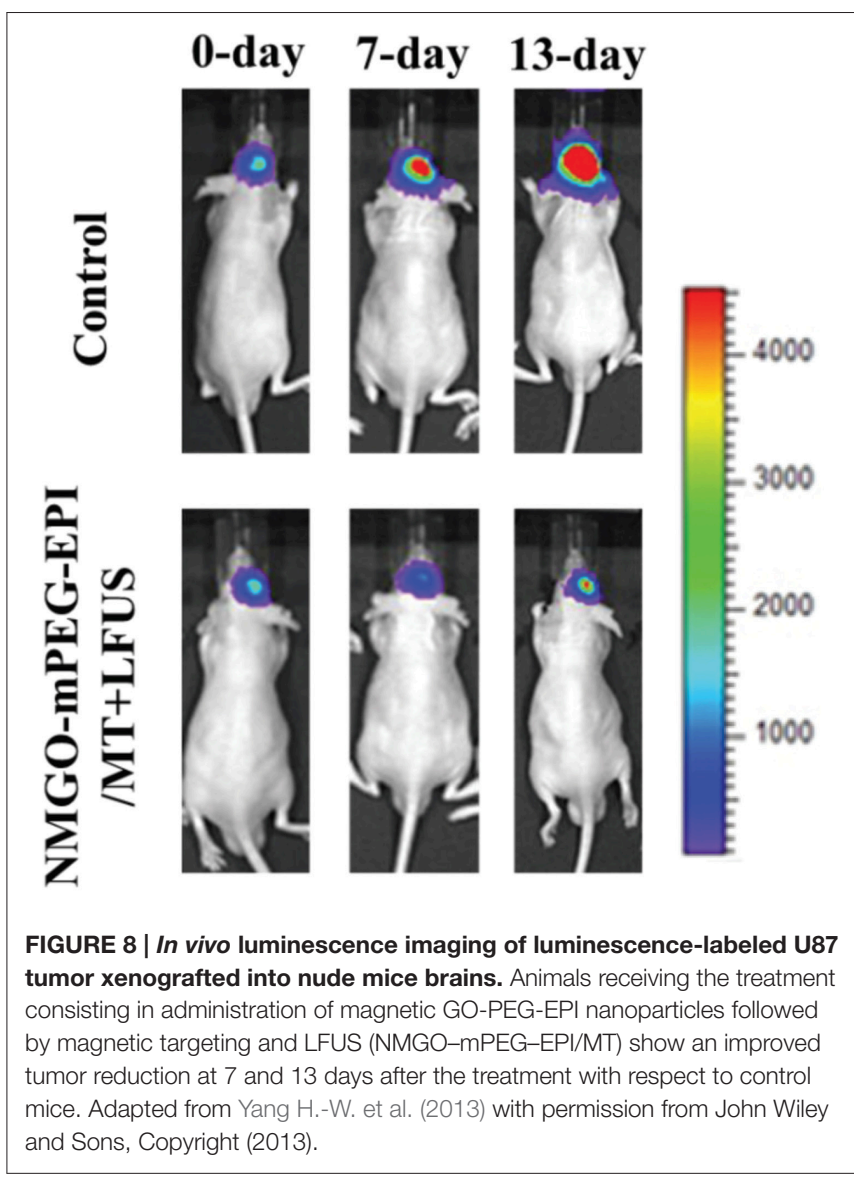

of the brain and the other tissues. Also, tumor DOX retention is increased with respect to controls. As result, Tf-PEG-GODOX nanoparticles can significantly delay the tumor growth and increase the rats median survival time, although no complete tumor eradication is noticed. Similarly, GO-PEG (100-300 nm lateral size) functionalized with Human Immunodeficiency Virus (HIV) Tat protein derived peptide (Tat), which increases the $\mathrm{BBB}$ permeability of the nanomaterial, can deliver drug molecules inside the brain tissues (Yang et al., 2015). The targeted nanovector is able to improve the perfenidone (PERF) efficacy in the treatment of subarachnoid hemorrhage, whose success is limited by the scarce BBB penetration of the drug. Photoacustic imaging demonstrates that the nanodrug is able to accumulate in the brain after i.v. administration and that there is a clear improvement with respect to the standard PERF therapy in the PERF-induced water content increase close to the injured site. Finally, evaluation of BBB integrity after the nanocarrier administration reveals that its structure and function are not affected by the nanoparticles.

In conclusion, the studies above reported suggest that GO and its derivatives have many properties that can make them suitable candidates for both diagnostic and therapeutic applications in the CNS: they display intrinsic fluorescence and they can diffuse inside the brain tissues, they have high loading capacity that allows them to deliver significant quantities of drugs or imaging agents inside the brain and, to date, they have not displayed 
toxicity toward CNS tissues yet. Unfortunately, the nanomaterial displays low BBB permeability per se, and functionalization with high efficiency targeting molecules or the employment of novel physical $\mathrm{BBB}$ opening techniques is mandatory in order to overcome this issue. We have to remark however that researches aiming to propose possible applications of GO in the CNS are relatively recent and therefore the nanomaterial has not been yet optimized (size, functionalization, dose, etc.) for the best performances in this body region. For the same reason, toxicity of GO toward CNS has not been deeply investigated, including a careful examination of GO effects both on single neuronal populations and in the whole CNS systematically evaluating the effect of size and functionalization. It is expected that the high attention given nowadays to graphene and derivatives will stimulate rapid improvements both in GO engineering for medical applications, including those involving the CNS, and in the understanding of its eventual toxic effects there.

\section{NANODIAMONDS}

Nanodiamonds (NDs) are carbon particles formed by $\mathrm{sp}^{3}$ carbon atoms arranged in a diamond-like cubic lattice. They can be produced in several diameters, ranging from 4-5 to $100 \mathrm{~nm}$ (Figure 9). NDs synthesis is usually performed at high pressurehigh temperature. Although several production methods were developed, the most used is detonation of TNT and nitroamines (RDX) (Galli, 2010; Mochalin et al., 2011). NDs are currently the most abundantly produced carbon nanostructures due to the number of industrial applications where they are employed, especially for the lubricants and polishing industry and as part of novel high-performance nanocomposite materials (Mochalin et al., 2011).

Nanodiamonds surface is highly reactive and can be easily functionalized, as well as passivated (Liu et al., 2008; Vaijayanthimala and Chang, 2009; Chen et al., 2010; Rojas et al., 2011). Furthermore, by irradiating nanodiamonds with highenergy particles and subsequent annealing, it is possible to create nitrogen-vacancy centers that render the nanodiamond particles highly fluorescent in the VIS range $(500-800 \mathrm{~nm}$, with peak emission at $680 \mathrm{~nm}$ ) (Fu et al., 2007; Chang et al., 2008; Vaijayanthimala et al., 2012; Hegyi and Yablonovitch,

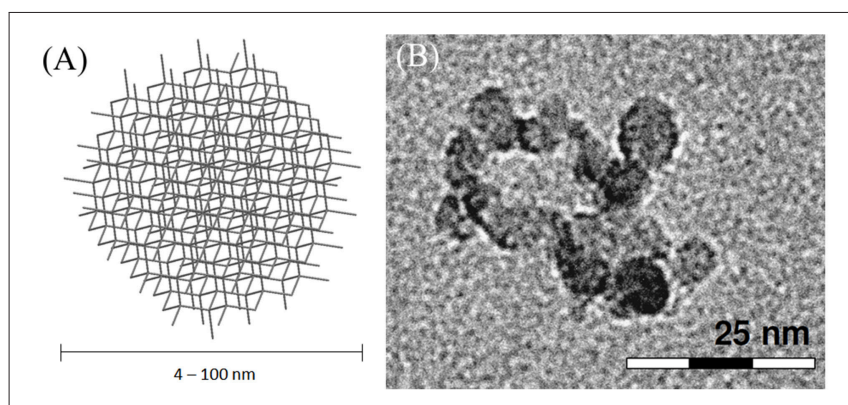

FIGURE 9 | (A) Schematic representation of NDs. (B) HRTEM micrograph of $\sim 7 \mathrm{~nm}$ oxidized diamond nanoparticles; adapted with permission from Rojas et al. (2011). Copiright (2011) American Chemical Society.
2013; Bartelmess et al., 2015c). Recently, they have started to be probed for possible biomedical applications like bioimaging (Vaijayanthimala and Chang, 2009; Hui et al., 2010; Hegyi and Yablonovitch, 2013; Perevedentseva et al., 2013), drug delivery and nucleic acid delivery (Xing and Dai, 2009; Chen et al., 2010; Zhu Y. et al., 2012; Perevedentseva et al., 2013), also exploiting the functionalization with targeting molecules for improved selectivity (Zhang X.-Q. et al., 2011; Fu et al., 2012). In view of their highly biocompatibility, nanodiamonds are one of the most promising carbon nanomaterials in this field (Schrand et al., 2007a,b, 2009; Perevedentseva et al., 2013; Monaco and Giugliano, 2014). When administered in vivo, nanodiamonds accumulate in the liver, in the spleen, and in lymphnodes (Yuan et al., 2009; Vaijayanthimala et al., 2012). Neuronal cells cultured on a surface of nanodiamonds reveal cell growth and electrophysiological properties comparable to neurons grown on classical supports (Thalhammer et al., 2010; Monaco and Giugliano, 2014; Edgington et al., 2013; Hopper et al., 2014). Nanodiamonds are internalized by various cell types, likely by chlatrin-based endocytosis (Liu K.-K. et al., 2009; Zhang X.-Q. et al., 2011), with limited or no cytotoxic effects being reported. Similar results are observed in neuronal cells (Hsu et al., 2014; Huang et al., 2014).

Despite the encouraging results both in vitro and in vivo for biological applications, in vivo applications of NDs in the CNS are still in their early days. To date only one report suggests the possible use of NDs for therapeutic applications in the CNS: CED (convection-enhanced delivery, an experimental high efficiency intracranial delivery system) of DOX-loaded NDs $(4-8 \mathrm{~nm})$ is found to provide efficient treatment of different aggressiveness gliomas xenographted in mice striatum (Xi et al., 2014). The treatment allows to extend mice survival (with respect to DOX treatment) 1.4 times in the case of the most aggressive tumor and 1.8 times in the case of the less aggressive one. Notably, in the latter case tumor is eradicated in 3 out of 5 mice, while all mice treated with non-conjugated DOX die. Experiments performed using healthy mice indicate that, while the intracerebral injection of a DOX solution cause the drug to rapidly spread in the whole brain producing tissue damage and brain edema, the use of NDsDOX and CED allows the therapeutic agent to be confined in the injection site, reducing its toxic effects on the surrounding tissues and increasing the concentration of the drug at the injection site. Furthermore, while DOX is rapidly excreted from the brain, NDs-DOX display a much lower clearance.

Alongside the possible applications of NDs in the CNS are being suggested, also toxicological studies in this body region start to be performed. Available data indicate that 100 $\mathrm{nm}$ fluorescent NDs injected in mice hippocampus do not produce any relevant effect neither on mice body weight, food or water intake, nor on mice behavior in a novel object recognition test, which should reveal eventual hippocampal damages (Huang et al., 2014). Interestingly, the same NDs have shown in vitro a concentration-dependent negative role in neuronal morphogenesis, although this effect seems due to a physical impairment of growth cones and not to the interference with the cytoskeletal proteins, as on the contrary it has been often evidenced for non-carbon nanoparticles (Tay et al., 2014). 
It is possible to hypothesize that the $3 \mathrm{D}$ environment and the presence of glial cells in the living tissue is drastically limiting the nanomaterial effects on growing neurons.

Given the low amount of data available, it is difficult to draw conclusions regarding the possibility of a successful application of nanodiamonds in brain science. The exclusive use of in situ delivery methods in the CNS raises the question if diamond nanoparticles can cross the $\mathrm{BBB}$ and therefore if they are suitable for applications in drug delivery or imaging in the brain. However, the possibility to display bright and photostable fluorescence, the encouraging results obtained in vitro, their ability to provide efficient and prolonged delivery of a drug while confining its site of action in a limited space and the absence of reports indicating relevant toxicity of the nanomaterial toward neuronal cells suggest that NDs may give precious contributions to the diagnosis and therapy of CNS diseases. It should be underlined again that the nanomaterial is in its early years of development for biomedical applications, especially in the neurosciences field. We hope that, as in the case of GO, suitable tailoring of the nanomaterial chemical, morphological and physical properties will help to overcome its current limitations.

\section{CARBON NANOHORNS AND CARBON NANOFIBERS}

Single-wall carbon nanohorns (SWCNHs) are relatively unexplored carbon nanomaterials, especially in biological studies. They are structurally similar to carbon nanotubes, however the continuous graphitic surface is arranged in a conical shape with a closed tip. They are usually 40-50 nm long and 2-3 nm wide, and they commonly assembly into $80-100 \mathrm{~nm}$ spherical aggregates (Iijima et al., 1999; Zhu and Xu, 2010; Figure 10). SWCNHs have been functionalized either covalently and noncovalently using the synthetic strategies developed for CNTs and graphene (Tagmatarchis et al., 2006; Cioffi et al., 2007; Pagona et al., 2007; Voiry et al., 2015). They find possible applications as gas storage materials (Adelene Nisha et al., 2000; Bekyarova et al., 2003; Yang et al., 2005; Sano et al., 2014), as supports for metal catalyst nanoparticles (Yoshitake et al., 2002; Kosaka et al., 2009), as electrode materials and as components of photovoltaic devices (Vizuete et al., 2010; Lodermeyer et al., 2015). Among biomedical applications, biomolecule sensing (Valentini et al., 2014), MRI imaging (as support) (Miyawaki et al., 2006), photodynamic and photothermal therapy of cancer (Zhang et al., 2008; Whitney et al., 2011; Chen et al., 2014) as well as drug and gene delivery (Murakami et al., 2004; Ajima et al., 2005, 2008; Guerra et al., 2014; Ma et al., 2014; Zhao Q. et al., 2015) are successfully achieved both in vitro and in vivo by SWCNHs.

Although SWCNHs are structurally similar to CNTs, their synthesis is metal-free, therefore no toxic effects due to metal contaminants are possible. However toxicity reports are conflicting: in some studies SWCNHs are found to be biocompatible in vitro as well as in vivo even at high doses despite their accumulation in several tissues like lung, spleen

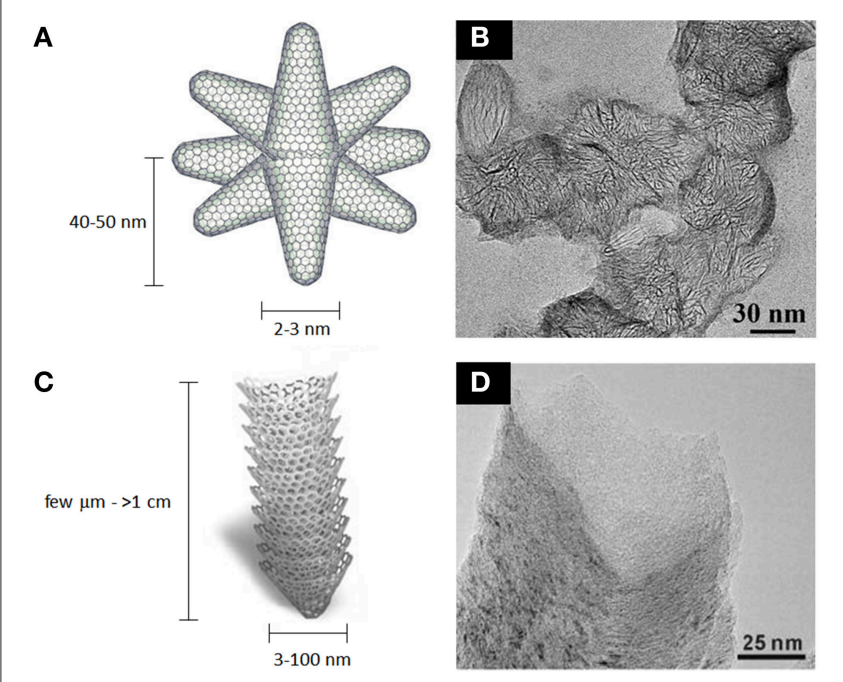

FIGURE 10 | Schematic representation of SWCNHs (A) and stacked-cup CNFs (C). (B) TEM micrograph of $\sim 80 \mathrm{~nm}$ SWCNHs peapods. (D) TEM micrograph of stacked-cup CNFs. (A,B) adapted from Voiry et al. (2015) with permission from The Royal Society of Chemistry. (C,D) adapted from Sato et al. (2005) with permission from The Royal Society of Chemistry.

and liver (Lynch et al., 2007; Miyawaki et al., 2008; Tahara et al., 2011), while other reports demonstrate their toxicity toward macrophages even at low doses (Yang M. et al., 2014). Toxicological reports regarding carbon nanohorns in vivo and in vitro are very limited however, and it is not possible to draw clear conclusions basing on state of the art literature, although the relative higher abundance of studies indicating the presence of just low and transitory toxicity suggests their compatibility with living tissues and organs.

Unfunctionalized SWCNHs are reported to be uptaken by mammalian cells, even if in a negligible amount (Isobe et al., 2006; Zhang M. et al., 2012), while when opportunely functionalized they can efficiently penetrate target cells, potentially allowing higher selectivity than other nanoparticles (Zhang M. et al., 2012; Li N. et al., 2015) and showing good carrier properties (Tahara et al., 2011).

To date only one report describes the successful delivery of SWCNHs in the brain. SWCNHs peapods, functionalized with CdSe/ZnSe quantum dots (QDs), encapsulating $\mathrm{Gd}_{3} \mathrm{~N} @ \mathrm{C}_{80}$ fullerenes and delivered to U87 tumor bearing mice by CED intratumoral infusion (Zhang et al., 2010c), enable tumor imaging either in vivo by MRI (thanks to $\mathrm{Gd}^{3+}$ ) and ex vivo by confocal microscopy (thanks to QDs). Data demonstrate also that SWCNHs can be retained inside the tumor for at least 3 days. Although this study indicates SWCNHs as a possible brain drug delivery nanoplatform, further reports aiming to determine the in vivo biodistribution of SWCNHs demonstrate that they are not able to cross the BBB (Miyawaki et al., 2009; Tahara et al., 2011). This precludes the SWCNHs to be delivered in the brain by i.v. administration, leaving the more dangerous and complicated intracranial administration as the only feasible option available at the moment. 
Carbon nanofibers (CNFs) are tubular carbon nanostructures, with diameters in the range of 3-100 $\mathrm{nm}$ and lengths that can also exceed $1 \mathrm{~cm}$ (De Jong and Geus, 2000; Figure 10). They are essentially made of assembled curved graphitic layers arranged in different ways to form long fibers, often hollow. They are usually synthesized using CVD methods employing metal catalysts (De Jong and Geus, 2000), or from electrospun polymer fibers carbonization (Inagaki et al., 2012). Their surface can be functionalized (Klein et al., 2008; Wang and Lin, 2008) or furthermore graphitized by thermal treatment (Ramos et al., 2013). Since their first discovery in the early 50's, these materials have been tested for several applications, like catalysis and energy storage (Rodriguez et al., 1994; Ji and Zhang, 2009; Wang K. et al., 2009; Duan et al., 2015), as well as for the preparation of many composite materials (Hammel et al., 2004). Moreover, they are used as support material for biomolecules sensing (Baker et al., 2006; Wang and Lin, 2008; Huang et al., 2010; Rand et al., 2013; Lim and Ahmed, 2015), gene delivery (McKnight et al., 2003) and in regenerative medicine (Webster et al., 2004; Tran et al., 2009). As for CNTs, several concerns regarding their toxicity have been advanced (Sato et al., 2005; Castranova et al., 2013), pointing out also their non-biodegradability and their asbestos-like accumulation in lungs.

Carbon nanofibers are proposed as coating materials for neural prosthetic devices, as they show good compatibility with neuronal cells and demonstrate to favor neuronal $v s$. glial/astrocytic proliferation (Webster et al., 2004; Tran et al., 2009). Also, carbon fibers can be used to build free-standing vertically aligned arrays that allow to support and organize the neuronal cells growth providing mechanical, chemical and electrical cues at the subcellular scale. They can be also employed to produce microelectrode arrays with possible applications for in vivo signal detection and manipulation (McKnight et al., 2006; Nguyen-Vu et al., 2007; de Asis et al., 2009; Zhang H. et al., 2012; Vitale et al., 2015).

Despite the longstanding experience on these nanomaterials and the deep knowledge of the nanofiber-neuron interface for the preparation of efficient microelectrodes, in vivo experiments on their possible application for the treatment of CNS injuries and diseases are limited to just one example (Moon et al., 2012). In this report CNFs impregnated with subventricular stem cells were employed to promote neuroregeneration after MCAO-induced stroke, evaluating also the differences between "hydrophobic" CNFs (i.e., thermally graphitized, HP-CNFs, 100 $\mathrm{nm} \times<5 \mu \mathrm{m}$ ) and "hydrophilic" CNFs (i.e., untreated CNFs, HL-CNFs, $60 \mathrm{~nm} \times<5 \mu \mathrm{m}$ ) after their injection in the lesion site. The animals receiving the CNF-based treatment show reduction of the infarcted volume as well as recovery of motor and somatosensory activity, with HP-CNFs treated animals showing moderately better performances. Distribution analysis of stem cells in the brain tissues indicates that while unsupported stem cells are migrating all over the infarcted area, CNFs-supported cells localize near the corpus callosum (HL-CNFs) or the striatum (HP-CNFs). Notably, HP-CNFs are able to promote the stem cells differentiation into neurons, to induce the formation of synapsis and to reduce the astrocytes and microglia recruitment with superior efficiency with respect to HL-SWCNTs and unsupported cells. These data indicate that CNFs are optimal support material for neuronal tissue regeneration, and that a lower surface wettability is also playing a key role in promoting the stem cell differentiation toward the neuronal fate.

Although the two studies indicate that both SWCNHs and CNFs can play a role as support materials for imaging or delivery applications, they both do not display BBB crossing capabilities and require in situ administration. Since their very big size it is unlikely that also advanced physical BBB opening techniques or chemical functionalization can help in this sense. Due to the limited possibilities of use alongside the indications of possible toxicity, few efforts have been dedicated to identify their possible applications in the diagnosis and cure of CNS diseases. However, when used as electrodes or as part of composite nanostructures, CNFs are found to be excellent materials for promoting neuronal stimulation and growth, showing also no local toxicity. While it is likely that SWCNHs applications in the CNS will not be further explored, it is expected that CNFs will have an important role in the development of neuronal recording and stimulating devices as well as in neuroregeneration applications.

\section{CARBON DOTS}

Carbon dots (CDs), are a recently discovered class of quasispherical carbon-based nanomaterials (Xu et al., 2004) which essentially combine the presence of an amorphous or nanocrystalline $\left(\mathrm{Csp}^{3}\right)$ core and a graphitic or turbostratic $\left(\mathrm{Csp}^{2}\right)$ shell (Figure 11). Many strategies have been developed for the synthesis of these materials, either using top-down and bottom-up approaches; however, the industrial scalability of their production is still difficult to date (Baker and Baker, 2010; Li H. et al., 2012; Lim et al., 2015; Zhang and Yu, in press). Their peculiar properties are exploited in photocatalysis (Fernando et al., 2015), electrocatalysis (Shen et al., 2015), as sensitizers for solar cells (Briscoe et al., 2015), as well as for sensing applications (Zhao A. et al., 2015). Due to their high intrinsic fluorescence which can span from the VIS to the NIR (Li H. et al., 2012; Strauss et al., 2014), CDs are considered particularly appealing for bioimaging applications (Cao et al.,

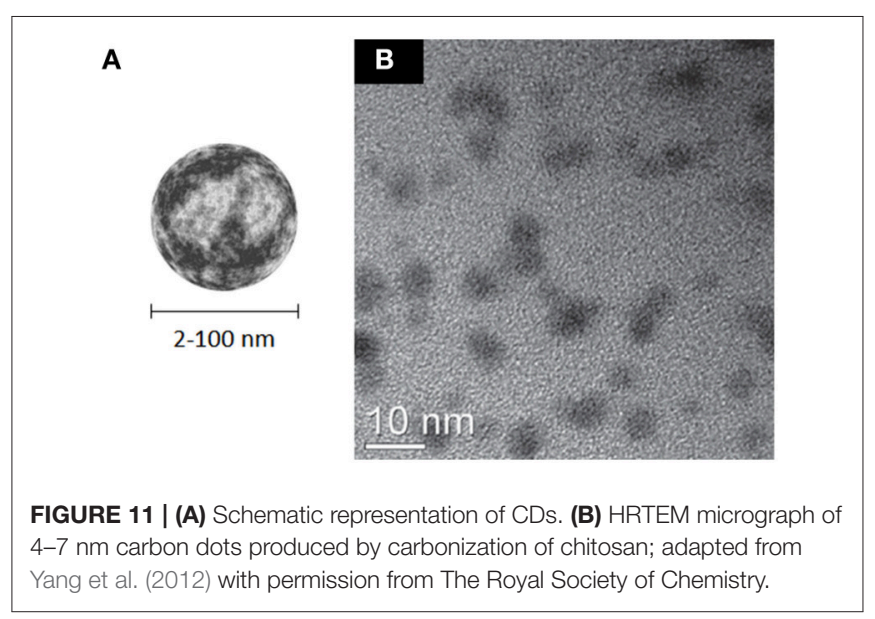


2012; Liu Q. et al., 2013; Luo et al., 2013; Ruan et al., 2014; Zhang and $\mathrm{Yu}$, in press), although the general excitation wavelength dependence of fluorescence emission (Sun et al., 2006; Liu et al., 2007; Qiao et al., 2010; Qu et al., 2012) can lead to artifact when they are used in combination with other luminescent probes. Depending on the synthetic strategy adopted, they already expose on their surface functional groups that allow surface passivation with biocompatible polymers and to graft additional relevant molecules (Li et al., 2010; Liu et al., 2012; Wu et al., 2013). Finally, molecules like anticancer drugs and nucleic acids can be noncovalently loaded on their surface, allowing to use these nanomaterials for delivery purposes (Lai et al., 2012; Liu et al., 2012). Among all the carbon nanomaterials described so far, carbon dots seem to display the highest biocompatibility (Zhao et al., 2008; Yang et al., 2009a,b; Li et al., 2010; Liu et al., 2010; Chandra et al., 2011; Wang Y. et al., 2011; Tao et al., 2012; Qian et al., 2014; Ruan et al., 2014). One important contribution to this effect seems to be the high density of charged groups on their surface, which provides high stability of their suspensions in water and biological fluids.

Several authors report that carbon dots penetrate cell lines when applied in vitro (Qiao et al., 2010; Liu C. et al., 2011; Wang F. et al., 2011; Yang et al., 2012). No toxicity is observed in various studies conducted on cell lines (Liu R. et al., 2009; Yang et al., 2009b; Wang F. et al., 2011) and on animals (Qiao et al., 2010; Tao et al., 2012). However, a recent report indicates that these nanoparticles could interfere with exocytotic mechanisms, and therefore hamper the normal neuronal and brain functions (Borisova et al., 2015). Since the effect of CDs on cellular biochemistry has not been completely unraveled, caution should be used when investigating these nanomaterials for possible clinically relevant applications.

Given their recent discovery, only few studies have been probing CDs in the CNS in view of a potential use in the diagnosis and therapy of CNS diseases. To date, in vivo evidences fostering the CDs use in this field derive only from biodistribution studies. Interestingly, the CDs used in these studies exhibit very good BBB crossing capabilities and a strong preference to accumulate in the brain over the other organs although they were not endowed of specific functionalizations: $100 \mathrm{~nm}$ fluorescent CDs, prepared via the inexpensive and efficient pyrolysis of a glucose and glutamic acid mixture, demonstrate to be efficiently uptaken by cerebral tissues after i.v. administration in mice (Qian et al., 2014). Epifluorescence imaging, made possible thanks to the CDs bright fluorescence emission, reveals that they can readily cross the BBB after systemic injection and diffuse in the brain tissues, where they reach the highest concentration within $1 \mathrm{~h}$. Ex vivo imaging of brain slices indicates that these carbon dots are predominantly accumulating at the cortex surface, in the hippocampus and in the ventricles. Authors hypothesize that the presence of still intact glucose and glutamine molecules on the CDs surface endows the nanoparticles of "CNS-targeting" capabilities. From the available epifluorescence images, the nanomaterial does not show to diffuse in other specific body regions apart from the brain and the blood. Interestingly, the nanomaterial is also rapidly cleared from the CNS. In vitro studies demonstrate that CDs dispersions in plasma have high stability, they have good hemocompatibility and they are just moderately cytotoxic for brain endothelial cells only at very high concentrations. In summary the provided in vivo data, although referring only to early timepoints, suggest that the nanomaterial has an adequate safety profile for biomedical applications in the CNS.

Also 3-4 nm glycine-derived CDs are able to cross very efficiently the BBB and accumulate in the brain. Moreover, they are able to target a human glioma tumor xenographted in mice brain (Ruan et al., 2014). Epifluorescence imaging indicates that they display a maximum brain uptake just $5 \mathrm{~min}$ after the tail vein injection, they strongly localize inside the tumor mass and they are also rapidly cleared. Systemically, they are also distributing in liver, kidneys and hearth (Figure 12). In vitro hemolysis, plasma stability and cytotoxicity studies indicate a very high biocompatibility of this nanomaterial. Although these CDs display fast and consistent accumulation inside the tumor, their potential use as vectors for delivering antitumor drugs in the CNS is not suggested at the moment because of their fast excretion form the tumor lesion and their accumulation in the heart, which is a known target of anticancer drugs toxicity.

Despite their fast elimination from brain tissues, CDs represent an excellent starting point for the development of novel diagnostic and therapeutic systems against CNS pathologies thanks to their spontaneous BBB crossing capabilities, which seem not to depend from the nanomaterial size. Moreover, these nanomaterials are in the very early stages of development for biomedical applications: opportune chemical modifications with molecules able to increase their plasma circulation time and/or with targeting moieties will be able to improve their retention in the brain and to allow this way to exploit them for applications like tumor therapy. A deep toxicological evaluation of their effects in the CNS in particular but also in the whole body however must be undertaken since current data, albeit very promising, are not sufficient to draw clear conclusions.

\section{CONCLUSIONS AND PERSPECTIVES}

Carbon nanomaterials are often proposed as optimal candidates for neurobiomedical applications because of their properties which include low toxicity, high mechanical strength, high thermal and electric conductivity, and, in some cases, intrinsic fluorescence. The collection of studies and results presented in this review also demonstrates that these materials can interface with cerebral tissues, and that they can perform imaging, neuronal growth, neuroprotection and drug delivery tasks with high efficiency. Moreover, the wide variety of available carbon nanomaterials offers numerous possibilities for tailor-made actions and performances within the CNS (Table 1).

Carbon nanotubes, amongst carbon nanomaterials, are the most studied in vivo for possible applications in the diagnosis and cure of brain diseases. CNTs display good compatibility with brain tissues, neuroprotective effects against stroke-induced neurodegeneration, drug and nucleic acids delivery capabilities as well as support capabilities for neuroregeneration applications. Despite these promising performances, there are still some concerns about their toxicity, which has been shown to depend 

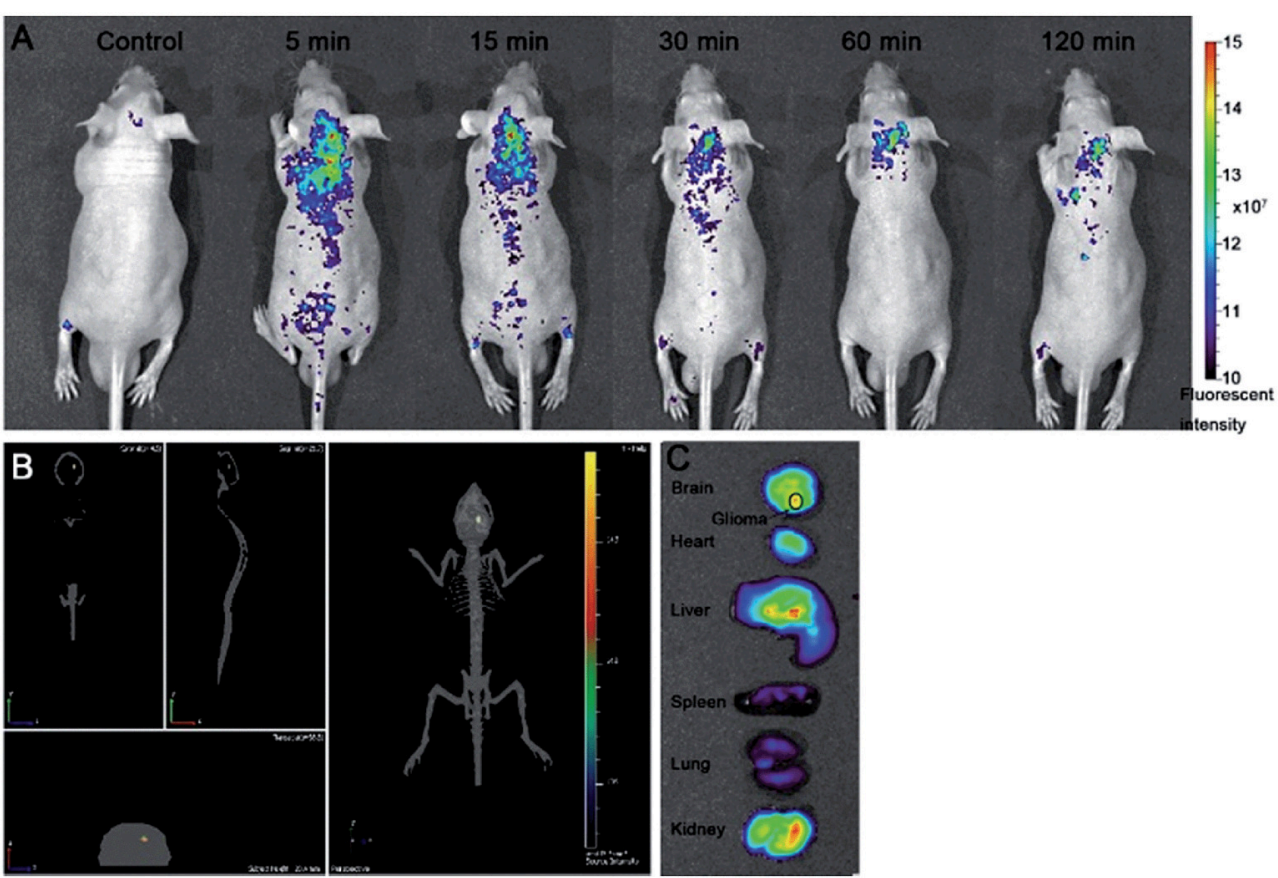

FIGURE 12 | In vivo and ex vivo imaging of glioma bearing mice after administration of 3-4 nm glycine-derived CDs. (A) Epifluorescence imaging of CDs distribution after i.v. injection, showing the rapid accumulation inside the glioma and the fast excretion of the nanoparticles after few hours. (B) 3-D reconstruction of CDs distribution $2 \mathrm{~h}$ after the injection, confirming the localization in the brain. (C) Ex vivo fluorescence imaging of main organs $2 \mathrm{~h}$ after CDs injection, indicating high accumulation in liver and kidney but also a good retention inside the glioma. Reproduced from Ruan et al. (2014) with permission from The Royal Society of Chemistry.

mostly on the CNTs administration site, on their agglomeration state and on the presence of metal impurities in the material. The studies reported in this review indicate that CNTs seldom show toxicity toward brain tissues, probably thanks to the high purity and high dispersibility of the nanomaterials used. To date, the biggest impairment to the CNTs implementation in the therapy of CNS diseases is represented by the elimination of the catalyst metal nanoparticles, which requires the use of several procedures that hamper a cost-effective, large-scale production of high purity material.

Fullerenes have also shown good potential to find applications in the CNS, given their BBB crossing capabilities. The focus on their applications in the CNS however has been predominantly directed to exploit their intrinsic neuroprotective behavior, while other applications like drug delivery and imaging have been rarely investigated. Despite fullerenes can be synthesized in large quantities and at relatively low costs, their toxicity, which is more evident in water-soluble derivatives (i.e., the most appealing for the integration into a drug product) than in unfunctionalized fullerenes, represents a serious obstacle and currently limits their practical use in therapy.

Graphene oxide and derivatives can be successfully applied in the CNS for imaging applications by exploiting their intrinsic NIR fluorescence or the functionalization with MRI contrast agents. Moreover they can deliver therapeutic drugs and genetic material inside cerebral tumors. On the other hand, they are unable to cross the BBB unless appropriately functionalized or with the help of physical BBB opening methodologies. Although they tend to accumulate in lungs and they persist in the body for a longer time than other carbon nanomaterials, their low-toxicity profile, especially in the presence of extensive functionalization, makes them possible candidates for future implementations in therapy.

Nanodiamonds have been proposed very recently as suitable nanomaterials for biomedical applications. Indeed, studies of their application in vivo are still very limited compared to those available for other carbon nanomaterials. Nevertheless, NDs have already shown promising drug delivery capabilities inside the CNS, which allowed to obtain several improvements in the therapy of a cerebral tumor with doxorubicin. Moreover, NDs have not displayed any alarming toxicity. Although the research on possible diagnostic and therapeutic applications of NDs in the brain is in its infancy, the current results suggest that these nanomaterials may have an important role to play in the future brain medicine.

Carbon nanohorns and nanofibers demonstrate to have strong limitations for their direct application in the CNS: both of them do not show BBB crossing capabilities, and there are strong concerns regarding their toxicity and their strong accumulation in several organs. For these reasons the number of studies in the CNS conducted over the years is limited. We do not envisage therefore a future for the direct use of these nanomaterials in the therapy of CNS diseases. 
TABLE 1 | Comparison of the experimental settings and main features of the different carbon nanomaterials.




TABLE 1 | Continued

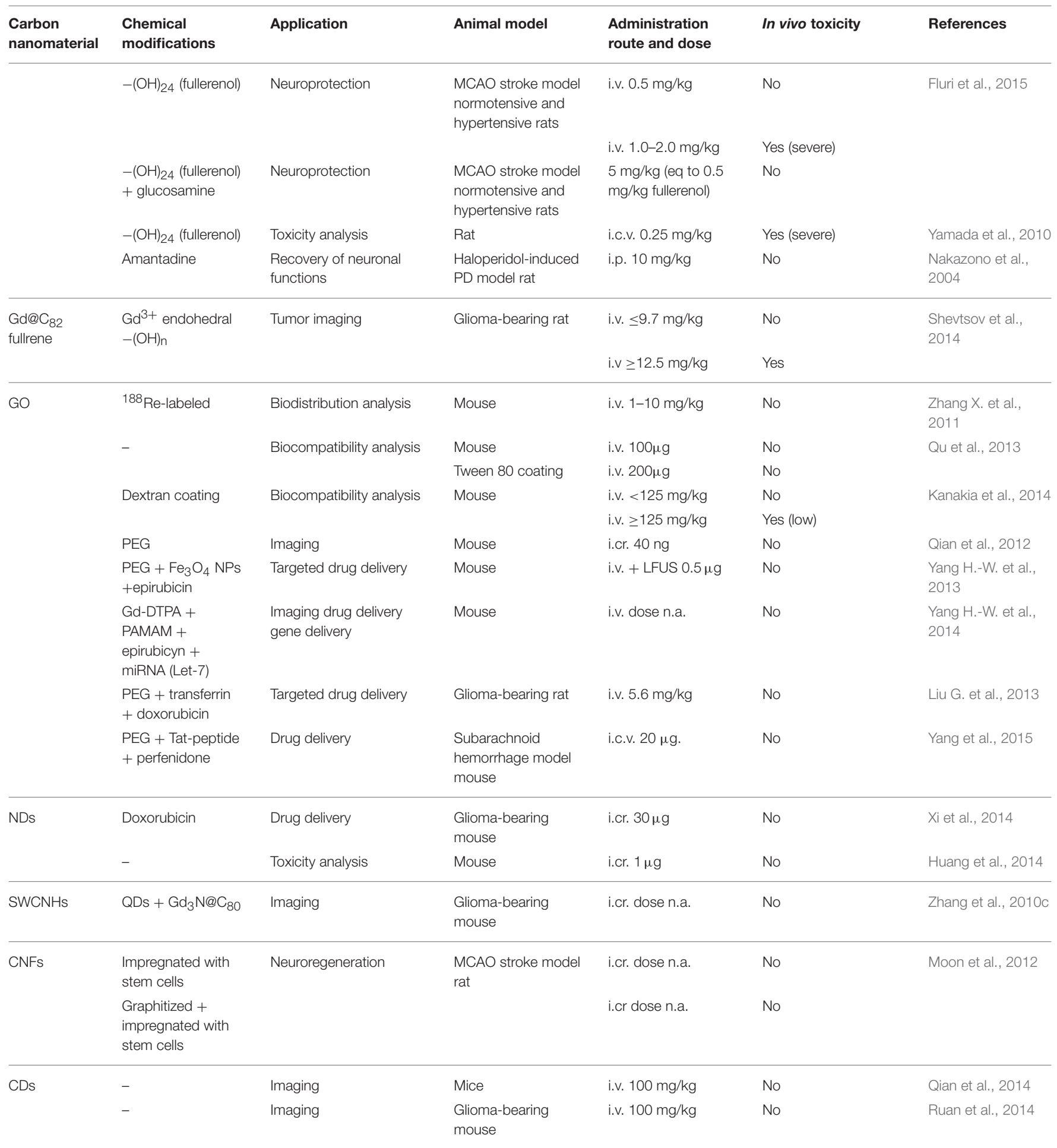

g.i., gastrointestinal; i.cr., intracranial; i.p., intraperitoneal; i.v., intravenous; i.c.v., intraventricular; s.c., subcutaneous.

Carbon dots are the latter discovered materials that have been examined for their possible implementation in the diagnosis and therapy of CNS diseases. For this reason, drug delivery or neuroprotection applications have not been evaluated in vivo yet. Nevertheless, biodistribution data indicate that carbon dots can cross the $\mathrm{BBB}$ very efficiently, and have a low retention in the body. Furthermore, there are only little evidences indicating their possible toxicity, which in any case seems to be very mild. Along with NDs, CDs therefore represent a very promising family of nanomaterials for future applications in brain diseases 
therapy and diagnosis. One current drawback is related to the fact that large-scale industrial production is still not technologically possible, even though the synthesis is relatively easy and cheap on a laboratory scale.

As highlighted in this review, research on carbon nanomaterials for brain-related applications is very active, and is taking full advantage of a combination of a broad spectrum of nanomaterials differing in their shape and properties and of a wealth of functional molecules that can provide them with additional tailored features. In vivo studies in the CNS represent a springboard for the implementation of carbon nanomaterials in the diagnosis and treatment of brain diseases. With this in mind, the studies herein presented offer an intriguing glimpse of what the continuous advancements in carbon nanomaterials technology will be able to provide in the near future. The number of different carbon nanostructures employed in brain research has increased dramatically in the last few years, yet there are some carbon nanomaterials that have not been investigated in this context already. Also, the success of NDs and CDs for biomedical applications indicates a higher potential for spherical carbon nanoparticles, both in

\section{REFERENCES}

Adelene Nisha, J., Yudasaka, M., Bandow, S., Kokai, F., Takahashi, K., and Iijima, S. (2000). Adsorption and catalytic properties of single-wall carbon nanohorns. Chem. Phys. Lett. 328, 381-386. doi: 10.1016/S0009-2614(00)00956-8

Ajima, K., Yudasaka, M., Murakami, T., Maigné, A., Shiba, K., and Iijima, S. (2005). Carbon nanohorns as anticancer drug carriers. Mol. Pharm. 2, 475-480. doi: $10.1021 / \mathrm{mp} 0500566$

Ajima, K., Murakami, T., Mizoguchi, Y., Tsuchida, K., Ichihashi, T., Iijima, S., et al. (2008). Enhancement of in vivo anticancer effects of cisplatin by incorporation inside single-wall carbon nanohorns. ACS Nano 2, 2057-2064. doi: $10.1021 / \mathrm{nn} 800395 \mathrm{t}$

Akhavan, O., and Ghaderi, E. (2013). Differentiation of human neural stem cells into neural networks on graphene nanogrids. J. Mater. Chem. B 1, 6291. doi: $10.1039 / \mathrm{c} 3 \mathrm{tb} 21085 \mathrm{e}$

Ali-Boucetta, H., Nunes, A., Sainz, R., Herrero, M. A., Tian, B., Prato, M., et al. (2013). Asbestos-like pathogenicity of long carbon nanotubes alleviated by chemical functionalization. Angew. Chemie Int. Ed. 52, 2274-2278. doi: 10.1002/anie.201207664

Al-Jamal, K. T., Toma, F. M., Yilmazer, A., Ali-Boucetta, H., Nunes, A., Herrero, M.-A., Tian, B., et al. (2010). Enhanced cellular internalization and gene silencing with a series of cationic dendron-multiwalled carbon nanotube:siRNA complexes. FASEB J. 24, 4354-4365. doi: 10.1096/fj.09-141036

Al-Jamal, K. T., Gherardini, L., Bardi, G., Nunes, A., Guo, C., Bussy, C., et al. (2011). Functional motor recovery from brain ischemic insult by carbon nanotube-mediated siRNA silencing. Proc. Natl. Acad. Sci. U.S.A. 108, 10952-10957. doi: 10.1073/pnas.1100930108

Andón, F. T., Kapralov, A. A., Yanamala, N., Feng, W., Baygan, A., Chambers, B. J., et al. (2013). Biodegradation of single-walled carbon nanotubes by eosinophil peroxidase. Small 9, 2720-2729. doi: 10.1002/smll.201202508

Andrews, R., Jacques, D., Qian, D., and Rantell, T. (2002). Multiwall Carbon Nanotubes: Synthesis and Application. Acc. Chem. Res. 35, 1008-1017. doi: $10.1021 /$ ar010151m

Aschberger, K., Johnston, H. J., Stone, V., Aitken, R. J., Tran, C. L., Hankin, S. M., et al. (2010). Review of fullerene toxicity and exposure - Appraisal of a human health risk assessment, based on open literature. Regul. Toxicol. Pharmacol. 58, 455-473. doi: 10.1016/j.yrtph.2010.08.017

de Asis, E. D., Nguyen-Vu, T. D. B., Arumugam, P. U., Chen, H., Cassell, A. M., Andrews, R. J., et al. (2009). High efficient electrical stimulation of hippocampal terms of biocompatibility and efficiency in cell penetration. In this sense carbon nano-onions, which have been recently tested for possible biomedical use, have the potential to contribute positively to neurobiomedical applications. We are confident that in the near future the knowledge acquired on the different carbon nanomaterials features and on their toxicology, alongside with the progress made in maximizing their performances in vivo, will allow these nanomaterials to assume an important role in the diagnosis and treatment of brain diseases.

\section{AUTHOR CONTRIBUTIONS}

SG and RT conceived the work. MB and MT performed the bibliographical search and drafted the manuscript. All authors contributed to the critical revision of the manuscript.

\section{ACKNOWLEDGMENTS}

Istituto Italiano di Tecnologia (IIT) is greatly acknowledged for funding.

slices with vertically aligned carbon nanofiber microbrush array. Biomed. Microdevices 11, 801-808. doi: 10.1007/s10544-009-9295-7

Baena, J. R., Gallego, M., and Valcárcel, M. (2002). Fullerenes in the analytical sciences. TrAC Trends Anal. Chem. 21, 187-198. doi: 10.1016/S01659936(02)00306-0

Baker, S. E., Tse, K.-Y., Lee, C.-S., and Hamers, R. J. (2006). Fabrication and characterization of vertically aligned carbon nanofiber electrodes for biosensing applications. Diam. Relat. Mater. 15, 433-439. doi: 10.1016/j.diamond.2005.08.019

Baker, S. N., and Baker, G. A. (2010). Luminescent carbon nanodots: emergent nanolights. Angew. Chemie Int. Ed. 49, 6726-6744. doi: 10.1002/anie.2009 06623

Bakry, R., Vallant, R. M., Najam-ul-Haq, M., Rainer, M., Szabo, Z., Huck, C. W., et al. (2007). Medicinal applications of fullerenes. Int. J. Nanomed. 2, 639-649.

Bardi, G., Tognini, P., Ciofani, G., Raffa, V., Costa, M., and Pizzorusso, T. (2009). Pluronic-coated carbon nanotubes do not induce degeneration of cortical neurons in vivo and in vitro. Nanomed. Nanotechnol. Biol. Med. 5, 96-104. doi: 10.1016/j.nano.2008.06.008

Bardi, G., Nunes, A., Gherardini, L., Bates, K., Al-Jamal, K. T., Gaillard, C., et al. (2013). Functionalized carbon nanotubes in the brain: cellular internalization and neuroinflammatory responses. PLOS ONE 8:e80964. doi: 10.1371/journal.pone.0080964

Bartelmess, J., Baldrighi, M., Nardone, V., Parisini, E., Buck, D., Echegoyen, L., et al. (2015c). Synthesis and characterization of far-red/NIR-fluorescent BODIPY dyes, solid-state fluorescence, and application as fluorescent tags attached to carbon nano-onions. Chem. A Eur. J. 21, 9727-9732. doi: 10.1002/chem. 201500877

Bartelmess, J., Frasconi, M., Balakrishnan, P. B., Signorelli, A., Echegoyen, L., Pellegrino, T., et al. (2015b). Non-covalent functionalization of carbon nanoonions with pyrene-BODIPY dyads for biological imaging. RSC $A d v$. 5, 50253-50258. doi: 10.1039/C5RA07683H

Bartelmess, J., De Luca, E., Signorelli, A., Baldrighi, M., Becce, M., Brescia, R., et al. (2014). Boron dipyrromethene (BODIPY) functionalized carbon nanoonions for high resolution cellular imaging. Nanoscale 6, 13761-13769. doi: 10.1039/C4NR04533E

Bartelmess, J., Quinn, S. J., and Giordani, S. (2015a). Carbon nanomaterials: multifunctional agents for biomedical fluorescence and Raman imaging. Chem. Soc. Rev. 44, 4672-4698. doi: 10.1039/C4CS00306C 
Bates, K., and Kostarelos, K. (2013). Carbon nanotubes as vectors for gene therapy: past achievements, present challenges and future goals. Adv. Drug Deliv. Rev. 65, 2023-2033. doi: 10.1016/j.addr.2013.10.003

Battigelli, A., Ménard-Moyon, C., Da Ros, T., Prato, M., and Bianco, A. (2013a). Endowing carbon nanotubes with biological and biomedical properties by chemical modifications. Adv. Drug Deliv. Rev. 65, 1899-1920. doi: 10.1016/j.addr.2013.07.006

Battigelli, A., Wang, J. T.-W., Russier, J., Da Ros, T., Kostarelos, K., Al-Jamal, K. T., et al. (2013b). Ammonium and guanidinium dendron-carbon nanotubes by amidation and click chemistry and their use for siRNA Delivery. Small 9, 3610-3619. doi: 10.1002/smll.201300264

Bekyarova, E., Murata, K., Yudasaka, M., Kasuya, D., Iijima, S., Tanaka, H., et al. (2003). Single-wall nanostructured carbon for methane storage. J. Phys. Chem. B 107, 4681-4684. doi: 10.1021/jp0278263

Bhattacharya, K., Sacchetti, C., El-Sayed, R., Fornara, A., Kotchey, G. P., Gaugler, J., et al. (2014). Enzymatic "stripping" and degradation of PEGylated carbon nanotubes. Nanoscale 6, 14686-14690. doi: 10.1039/c4nr03604b

Bianco, A., Kostarelos, K., Partidos, C. D., and Prato, M. (2005b). Biomedical applications of functionalised carbon nanotubes. Chem. Commun. 571-577. doi: $10.1039 / \mathrm{b} 410943 \mathrm{k}$

Bianco, A., Kostarelos, K., and Prato, M. (2005a). Applications of carbon nanotubes in drug delivery. Curr. Opin. Chem. Biol. 9, 674-679. doi: 10.1016/j.cbpa.2005.10.005

Bisaglia, M., Natalini, B., Pellicciari, R., Straface, E., Malorni, W., Monti, C., et al. (2000). C3-Fullero-tris-methanodicarboxylic acid protects cerebellar granule cells from apoptosis. J. Neurochem. 74, 1197-1204. doi: 10.1046/j.14714159.2000.741197.x

Borisova, T., Nazarova, A., Dekaliuk, M., Krisanova, N., Pozdnyakova, N., Borysov, A., et al. (2015). Neuromodulatory properties of fluorescent carbon dots: effect on exocytotic release, uptake and ambient level of glutamate and GABA in brain nerve terminals. Int. J. Biochem. Cell Biol. 59, 203-215. doi: 10.1016/j.biocel.2014.11.016

Brabec, C. J., Gowrisanker, S., Halls, J. J. M., Laird, D., Jia, S., and Williams, S. P. (2010). Polymer-fullerene bulk-heterojunction solar cells. Adv. Mater. 22, 3839-3856. doi: 10.1002/adma.200903697

Briscoe, J., Marinovic, A., Sevilla, M., Dunn, S., and Titirici, M. (2015). Biomass-derived carbon quantum dot sensitizers for solid-state nanostructured solar cells. Angew. Chemie Int. Ed. 54, 4463-4468. doi: 10.1002/anie.2014 09290

Bussy, C., Al-Jamal, K. T., Boczkowski, J., Lanone, S., Prato, M., Bianco, A., et al. (2015). Microglia determine brain region-specific neurotoxic responses to chemically functionalized carbon nanotubes. ACS Nano 9, 7815-7830. doi: 10.1021/acsnano.5b02358

Bussy, C., Hadad, C., Prato, M., Bianco, A., and Kostarelos, K. (2016). Intracellular degradation of chemically functionalized carbon nanotubes using a long-term primary microglial culture model. Nanoscale 590-601. doi: 10.1039/c5nr06625e

Cao, J., Wang, Q., and Dai, H. (2003). Electromechanical properties of metallic, quasimetallic, and semiconducting carbon nanotubes under stretching. Phys. Rev. Lett. 90, 157601. doi: 10.1103/PhysRevLett.90.157601

Cao, L., Yang, S.-T., Wang, X., Luo, P. G., Liu, J.-H., Sahu, S., et al. (2012). Competitive performance of carbon "quantum" dots in optical bioimaging. Theranostics 2, 295-301. doi: 10.7150/thno.3912

Cao, L., Meziani, M. J., Sahu, S., and Sun, Y.-P. (2013). Photoluminescence properties of graphene versus other carbon nanomaterials. Acc. Chem. Res. 46, 171-180. doi: 10.1021/ar300128j

Cassell, A. M., Raymakers, J. A., Kong, J., and Dai, H. (1999). Large scale CVD synthesis of single-walled carbon nanotubes. J. Phys. Chem. B 103, 6484-6492. doi: $10.1021 /$ jp990957s

Castranova, V., Schulte, P. A., and Zumwalde, R. D. (2013). Occupational nanosafety considerations for carbon nanotubes and carbon nanofibers. Acc. Chem. Res. 46, 642-649. doi: 10.1021/ar300004a

Cellot, G., Cilia, E., Cipollone, S., Rancic, V., Sucapane, A., Giordani, S., Gambazzi, L., Markram, H., Grandolfo, M., Scaini, D., et al. (2009). Carbon nanotubes might improve neuronal performance by favouring electrical shortcuts. Nat. Nanotechnol. 4, 126-133. doi: 10.1038/nnano.2008.374

Cellot, G., Ballerini, L., Prato, M., and Bianco, A. (2010). Neurons are able to internalize soluble carbon nanotubes: new opportunities or old risks? Small 6, 2630-2633. doi: 10.1002/smll.201000906
Cellot, G., Toma, F. M., Kasap Varley, Z., Laishram, J., Villari, A., Quintana, M., et al. (2011). Carbon nanotube scaffolds tune synaptic strength in cultured neural circuits: novel frontiers in nanomaterial-tissue interactions. J. Neurosci. 31, 12945-12953. doi: 10.1523/JNEUROSCI.1332-11.2011

Chandra, S., Das, P., Bag, S., Laha, D., and Pramanik, P. (2011). Synthesis, functionalization and bioimaging applications of highly fluorescent carbon nanoparticles. Nanoscale 3, 1533. doi: 10.1039/c0nr00735h

Chang, Y.-R., Lee, H.-Y., Chen, K., Chang, C.-C., Tsai, D.-S., Fu, C.-C., et al. (2008). Mass production and dynamic imaging of fluorescent nanodiamonds. Nat. Nanotechnol. 3, 284-288. doi: 10.1038/nnano.2008.99

Chao, T.-I., Xiang, S., Chen, C.-S., Chin, W.-C., Nelson, A. J., Wang, C., et al. (2009). Carbon nanotubes promote neuron differentiation from human embryonic stem cells. Biochem. Biophys. Res. Commun. 384, 426-430. doi: 10.1016/j.bbrc.2009.04.157

Chen, M., Zhang, X.-Q., Man, H. B., Lam, R., Chow, E. K., and Ho, D. (2010). Nanodiamond vectors functionalized with polyethylenimine for siRNA delivery. J. Phys. Chem. Lett. 1, 3167-3171. doi: 10.1021/jz10 13278

Chen, C. H., Lin, C. T., Chen, J. J., Hsu, W. L., Chang, Y. C., Yeh, S. R., et al. (2011). "A graphene-based microelectrode for recording neural signals," in 2011 16th International Solid-State Sensors, Actuators and Microsystems Conference (IEEE), 1883-1886. doi: 10.1109/TRANSDUCERS.2011.5969794

Chen, Z., Ma, L., Liu, Y., and Chen, C. (2012). Applications of functionalized fullerenes in tumor theranostics. Theranostics 2, 238-250. doi: 10.7150/thno.3509

Chen, D., Wang, C., Jiang, F., Liu, Z., Shu, C., and Wan, L.-J. (2014). In vitro and in vivo photothermally enhanced chemotherapy by single-walled carbon nanohorns as a drug delivery system. J. Mater. Chem. B 2, 4726. doi: $10.1039 / \mathrm{c} 4 \mathrm{tb} 00249 \mathrm{k}$

Cheung, W., Pontoriero, F., Taratula, O., Chen, A. M., and He, H. (2010). DNA and carbon nanotubes as medicine. Adv. Drug Deliv. Rev. 62, 633-649. doi: 10.1016/j.addr.2010.03.007

Chng, E. L. K., Sofer, Z., and Pumera, M. (2014). Cytotoxicity profile of highly hydrogenated graphene. Chem. A Eur. J. 20, 6366-6373. doi: 10.1002/chem.201304911

Chung, C., Kim, Y.-K., Shin, D., Ryoo, S.-R., Hong, B. H., and Min, D.-H. (2013). Biomedical applications of graphene and graphene oxide. Acc. Chem. Res. 46, 2211-2224. doi: 10.1021/ar300159f

Chwalibog, A., Sawosz, E., Jaworski, S., Kutwin, M., Hotowy, A., Wierzbicki, M., et al. (2014). Toxicity of pristine graphene in experiments in a chicken embryo model. Int. J. Nanomedicine 9, 3913. doi: 10.2147/IJN.S65633

Cioffi, C., Campidelli, S., Sooambar, C., Marcaccio, M., Marcolongo, G., Meneghetti, M., et al. (2007). Synthesis, Characterization, and Photoinduced Electron Transfer in Functionalized Single Wall Carbon Nanohorns. J. Am. Chem. Soc. 129, 3938-3945. doi: 10.1021/ja068007p

Dai, H. (2002). Carbon nanotubes: synthesis, integration, and properties. Acc. Chem. Res. 35, 1035-1044. doi: 10.1021/ar0101640

Dal Bosco, L., Weber, G. E. B., Parfitt, G. M., Paese, K., Gonçalves, C. O. F., Serodre, T. M., et al. (2015). PEGylated carbon nanotubes impair retrieval of contextual fear memory and alter oxidative stress parameters in the rat hippocampus. Biomed Res. Int. 2015, 1-11. doi: 10.1155/2015/104135

David-Pur, M., Bareket-Keren, L., Beit-Yaakov, G., Raz-Prag, D., and Hanein, Y. (2014). All-carbon-nanotube flexible multi-electrode array for neuronal recording and stimulation. Biomed. Microdevices 16, 43-53. doi: 10.1007/s10544-013-9804-6

De Jong, W. H., and Geus, J. W. (2000). Carbon nanofibers: catalytic synthesis and applications. Catal. Rev. 42, 481-510. doi: 10.1081/CR-100101954

De Volder, M. F. L., Tawfick, S. H., Baughman, R. H., and Hart, a J. (2013). Carbon nanotubes: present and future commercial applications. Science 339, 535-539. doi: $10.1126 /$ science. 1222453

Dhawan, A., Taurozzi, J. S., Pandey, A. K., Shan, W., Miller, S. M., Hashsham, S., et al. (2006). Stable colloidal dispersions of C 60 fullerenes in water: evidence for genotoxicity ${ }^{\dagger}$. Environ. Sci. Technol. 40, 7394-7401. doi: 10.1021/es06 09708

Duan, X., Ji, J., Qian, G., Zhou, X., and Chen, D. (2015). Recent advances in synthesis of reshaped $\mathrm{Fe}$ and $\mathrm{Ni}$ particles at the tips of carbon nanofibers and their catalytic applications. Catal. Today 249, 2-11. doi: 10.1016/j.cattod.2014.11.018 
Dubin, R. A., Callegari, G. C., Kohn, J., and Neimark, A. V. (2008). Carbon nanotube fibers are compatible with mammalian cells and neurons. IEEE Trans. Nanobiosci. 7, 11-14. doi: 10.1109/TNB.2008.2000144

Dugan, L. L., Gabrielsen, J. K., Yu, S. P., Lin, T.-S., and Choi, D. W. (1996). Buckminsterfullerenol free radical scavengers reduce excitotoxic and apoptotic death of cultured cortical neurons. Neurobiol. Dis. 3, 129-135. doi: 10.1006/nbdi.1996.0013

Dugan, L. L., Turetsky, D. M., Du, C., Lobner, D., Wheeler, M., Almli, C. R., et al. (1997). Carboxyfullerenes as neuroprotective agents. Proc. Natl. Acad. Sci. U.S.A. 94, 9434-9439. doi: 10.1073/pnas.94.17.9434

Dugan, L. L., Lovett, E. G., Quick, K. L., Lotharius, J., Lin, T. T., and O’Malley, K. L. (2001). Fullerene-based antioxidants and neurodegenerative disorders. Parkinsonism Relat. Disord. 7, 243-246. doi: 10.1016/S1353-8020(00)00064-X

Dugan, L. L., Tian, L., Quick, K. L., Hardt, J. I., Karimi, M., Brown, C., et al. (2014). Carboxyfullerene neuroprotection postinjury in Parkinsonian nonhuman primates. Ann. Neurol. 76, 393-402. doi: 10.1002/ana.24220

Edgington, R. J., Thalhammer, A., Welch, J. O., Bongrain, A., Bergonzo, P., Scorsone, E., et al. (2013). Patterned neuronal networks using nanodiamonds and the effect of varying nanodiamond properties on neuronal adhesion and outgrowth. J. Neural Eng. 10:056022. doi: 10.1088/1741-2560/10/5/056022

Elgrabli, D., Dachraoui, W., Ménard-Moyon, C., Liu, X. J., Bégin, D., BéginColin, S., et al. (2015). Carbon nanotube degradation in macrophages: live nanoscale monitoring and understanding of biological pathway. ACS Nano 9, 10113-10124. doi: 10.1021/acsnano.5b03708

Fabbro, C., Ali-Boucetta, H., Ros, T., Da Kostarelos, K., Bianco, A., and Prato, M. (2012). Targeting carbon nanotubes against cancer. Chem. Commun. 48, 3911. doi: $10.1039 / \mathrm{c} 2 \mathrm{cc} 17995 \mathrm{~d}$

Fabbro, A., Villari, A., Laishram, J., Scaini, D., Toma, F. M., Turco, A., et al. (2012). Spinal cord explants use carbon nanotube interfaces to enhance neurite outgrowth and to fortify synaptic inputs. ACS Nano 6, 2041-2055. doi: $10.1021 / \mathrm{nn} 203519 \mathrm{r}$

Fabbro, A., Sucapane, A., Toma, F. M., Calura, E., Rizzetto, L., Carrieri, C., Roncaglia, P., Martinelli, V., Scaini, D., Masten, L., et al. (2013). Adhesion to carbon nanotube conductive scaffolds forces action-potential appearance in immature rat spinal neurons. PLoS ONE 8:e73621. doi: 10.1371/journal.pone.0073621

Fabbro, A., Scaini, D., León, V., Vázquez, E., Cellot, G., Privitera, G., et al. (2016). Graphene-based interfaces do not alter target nerve cells. ACS Nano 10, 615-623. doi: 10.1021/acsnano.5b05647

Farrera, C., Bhattacharya, K., Lazzaretto, B., Andón, F. T., Hultenby, K., Kotchey, G. P., et al. (2014). Extracellular entrapment and degradation of single-walled carbon nanotubes. Nanoscale 6, 6974-6983. doi: 10.1039/c3nr06047k

Fernando, K. A. S., Sahu, S., Liu, Y., Lewis, W. K., Guliants, E. a., Jafariyan, A., et al. (2015). Carbon quantum dots and applications in photocatalytic energy conversion. ACS Appl. Mater. Interfaces 7, 8363-8376. doi: 10.1021 /acsami.5b00448

Fluri, F., Grünstein, D., Cam, E., Ungethuem, U., Hatz, F., Schäfer, J., et al. (2015). Fullerenols and glucosamine fullerenes reduce infarct volume and cerebral inflammation after ischemic stroke in normotensive and hypertensive rats. Exp. Neurol. 265, 142-151. doi: 10.1016/j.expneurol.2015.01.005

Frasconi, M., Maffeis, V., Bartelmess, J., Echegoyen, L., and Giordani, S. (2015a). Highly surface functionalized carbon nano-onions for bright light bioimaging. Methods Appl. Fluoresc. 3:044005. doi: 10.1088/2050-6120/3/4/044005

Frasconi, M., Marotta, R., Markey, L., Flavin, K., Spampinato, V., Ceccone, G., et al. (2015b). Multi-functionalized carbon nano-onions as imaging probes for cancer cells. Chem. A Eur. J. 21, 19071-19080. doi: 10.1002/chem.201503166

Freitas, R., A. (2005). What is nanomedicine? Nanomed. Nanotechnol. Biol. Med. 1, 2-9. doi: 10.1016/j.nano.2004.11.003

Fu, C.-C., Lee, H.-Y., Chen, K., Lim, T.-S., Wu, H.-Y., Lin, P.-K., et al. (2007). Characterization and application of single fluorescent nanodiamonds as cellular biomarkers. Proc. Natl. Acad. Sci. U. S. A. 104, 727-732. doi: 10.1073/pnas.0605409104

Fu, Y., An, N., Zheng, S., Liang, A., and Li, Y. (2012). BmK CT-conjugated fluorescence nanodiamond as potential glioma-targeted imaging and drug. Diam. Relat. Mater. 21, 73-76. doi: 10.1016/j.diamond.2011.10.010

Gabay, T., Jakobs, E., Ben-Jacob, E., and Hanein, Y. (2005). Engineered selforganization of neural networks using carbon nanotube clusters. Phys. A Stat. Mech. its Appl. 350, 611-621. doi: 10.1016/j.physa.2004.11.007
Gadd, G. E., Evans, P. J., Kennedy, S., James, M., Elcombe, M., Cassidy, D., Moricca, S., Holmes, J., Webb, N., Dixon, A., et al. (1999). Gas Storage in Fullerenes. Fuller. Sci. Technol. 7, 1043-1143. doi: 10.1080/106412299093 50304

Gaillard, C., Cellot, G., Li, S., Toma, F. M., Dumortier, H., Spalluto, G., et al. (2009). Carbon nanotubes carrying cell-adhesion peptides do not interfere with neuronal functionality. Adv. Mater. 21, 2903-2908. doi: 10.1002/adma.200900050

Galli, G. (2010). "Structure, stability and electronic properties of nanodiamonds," in Computer-Based Modeling of Novel Carbon Systems and Their Properties Carbon Materials: Chemistry and Physics, eds L. Colombo and A. Fasolino (Dordrecht: Springer), 37-57. doi: 10.1007/978-1-4020-9718-8

Gheith, M. K., Sinani, V. A., Wicksted, J. P., Matts, R. L., and Kotov, N. A. (2005). Single-walled carbon nanotube polyelectrolyte multilayers and freestanding films as a biocompatible platform for neuroprosthetic implants. Adv. Mater. 17, 2663-2670. doi: 10.1002/adma.200500366

Gheith, M. K., Pappas, T. C., Liopo, A. V., Sinani, V. A., Shim, B. S., Motamedi, M., et al. (2006). Stimulation of neural cells by lateral currents in conductive layerby-layer films of single-walled carbon nanotubes. Adv. Mater. 18, 2975-2979. doi: 10.1002/adma.200600878

Ghosh, M., Sonkar, S. K., Saxena, M., and Sarkar, S. (2011). Carbon nano-onions for imaging the life cycle of Drosophila melanogaster. Small 7, 3170-3177. doi: $10.1002 / \mathrm{smll} .201101158$

Giordani, S., Bartelmess, J., Frasconi, M., Biondi, I., Cheung, S., Grossi, M., et al. (2014). NIR fluorescence labelled carbon nano-onions: synthesis, analysis and cellular imaging. J. Mater. Chem. B 2, 7459-7463. doi: 10.1039/C4TB01087F

Goenka, S., Sant, V., and Sant, S. (2014). Graphene-based nanomaterials for drug delivery and tissue engineering. J. Control. Release 173, 75-88. doi: 10.1016/j.jconrel.2013.10.017

Gollavelli, G., and Ling, Y.-C. (2012). Multi-functional graphene as an in vitro and in vivo imaging probe. Biomaterials 33, 2532-2545. doi: 10.1016/j.biomaterials.2011.12.010

Gong, H., Peng, R., and Liu, Z. (2013). Carbon nanotubes for biomedical imaging: the recent advances. Adv. Drug Deliv. Rev. 65, 1951-1963. doi: 10.1016/j.addr.2013.10.002

Guerra, J., Herrero, M. A., and Vázquez, E. (2014). Carbon nanohorns as alternative gene delivery vectors. RSC $A d v$. 4, 27315. doi: 10.1039/c4ra03251a

Hahn, M., a., Singh, A. K., Sharma, P., Brown, S. C., and Moudgil, B. M. (2011). Nanoparticles as contrast agents for in-vivo bioimaging: current status and future perspectives. Anal. Bioanal. Chem. 399, 3-27. doi: 10.1007/s00216-0104207-5

Hammel, E., Tang, X., Trampert, M., Schmitt, T., Mauthner, K., Eder, A., et al. (2004). Carbon nanofibers for composite applications. Carbon 42, 1153-1158. doi: 10.1016/j.carbon.2003.12.043

Hegyi, A., and Yablonovitch, E. (2013). Molecular imaging by optically detected electron spin resonance of nitrogen-vacancies in nanodiamonds. Nano Lett. 13, 1173-1178. doi: 10.1021/nl304570b

Hong, H., Zhang, Y., Engle, J. W., Nayak, T. R., Theuer, C. P., Nickles, R. J., et al. (2012). In vivo targeting and positron emission tomography imaging of tumor vasculature with 66Ga-labeled nano-graphene. Biomaterials 33, 4147-4156. doi: 10.1016/j.biomaterials.2012.02.031

Hong, S. W., Lee, J. H., Kang, S. H., Hwang, E. Y., Hwang, Y. S., Lee, M. H., et al. (2014). Enhanced neural cell adhesion and neurite outgrowth on graphene-based biomimetic substrates. Biomed Res. Int. 2014:212149. doi: $10.1155 / 2014 / 212149$

Hong, G., Diao, S., Antaris, A. L., and Dai, H. (2015). Carbon nanomaterials for biological imaging and nanomedicinal therapy. Chem. Rev. 115, 10816-10906. doi: 10.1021/acs.chemrev.5b00008

Hopper, A. P., Dugan, J. M., Gill, A. A., Fox, O. J. L., May, P. W., Haycock, J. W., et al. (2014). Amine functionalized nanodiamond promotes cellular adhesion, proliferation and neurite outgrowth. Biomed. Mater. 9:045009. doi: 10.1088/1748-6041/9/4/045009

Hsu, T.-C., Liu, K.-K., Chang, H.-C., Hwang, E., and Chao, J.-I. (2014). Labeling of neuronal differentiation and neuron cells with biocompatible fluorescent nanodiamonds. Sci. Rep. 4:5004. doi: 10.1038/srep05004

Hu, H., Ni, Y., Montana, V., Haddon, R. C., and Parpura, V. (2004). Chemically functionalized carbon nanotubes as substrates for neuronal growth. Nano Lett. 4, 507-511. doi: $10.1021 /$ nl035193d 
Hu, X., and Zhou, Q. (2013). Health and ecosystem risks of graphene. Chem. Rev. 113, 3815-3835. doi: 10.1021/cr300045n

Huang, S. S., Tsai, S. K., Chih, C. L., Chiang, L.-Y., Hsieh, H. M., Teng, C. M., et al. (2001). Neuroprotective effect of hexasulfobutylated C60 on rats subjected to focal cerebral ischemia. Free Radic. Biol. Med. 30, 643-649. doi: 10.1016/S0891-5849(00)00505-0

Huang, J., Liu, Y., and You, T. (2010). Carbon nanofiber based electrochemical biosensors: a review. Anal. Methods 2, 202. doi: 10.1039/b9ay00312f

Huang, P. (2011). Folic Acid-conjugated graphene oxide loaded with photosensitizers for targeting photodynamic therapy. Theranostics 1:240. doi: 10.7150/thno/v01p0240

Huang, Y.-A., Kao, C.-W., Liu, K.-K., Huang, H.-S., Chiang, M.-H., Soo, C.-R., et al. (2014). The effect of fluorescent nanodiamonds on neuronal survival and morphogenesis. Sci. Rep. 4:6919. doi: 10.1038/srep06919

Hui, Y. Y., Cheng, C.-L., and Chang, H.-C. (2010). Nanodiamonds for optical bioimaging. J. Phys. D. Appl. Phys. 43:374021. doi: 10.1088/0022$3727 / 43 / 37 / 374021$

Iijima, S. (1991). Helical microtubules of graphitic carbon. Nature 354, 56-58. doi: $10.1038 / 354056 \mathrm{a} 0$

Iijima, S., Yudasaka, M., Yamada, R., Bandow, S., Suenaga, K., Kokai, F., et al. (1999). Nano-aggregates of single-walled graphitic carbon nano-horns. Chem. Phys. Lett. 309, 165-170. doi: 10.1016/S0009-2614(99)00642-9

Inagaki, M., Yang, Y., and Kang, F. (2012). Carbon nanofibers prepared via electrospinning. Adv. Mater. 24, 2547-2566. doi: 10.1002/adma.201104940

Isobe, H., Tanaka, T., Maeda, R., Noiri, E., Solin, N., Yudasaka, M., et al. (2006). Preparation, purification, characterization, and cytotoxicity assessment of water-soluble, transition-metal-free carbon nanotube aggregates. Angew. Chemie Int. Ed. 45, 6676-6680. doi: 10.1002/anie.200601718

Jan, E., Hendricks, J. L., Husaini, V., Richardson-Burns, S. M., Sereno, A., Martin, D. C., et al. (2009). Layered carbon nanotube-polyelectrolyte electrodes outperform traditional neural interface materials. Nano Lett. 9, 4012-4018. doi: $10.1021 / \mathrm{nl} 902187 \mathrm{z}$

Jastrzebska, A. M., Kurtycz, P., and Olszyna, A. R. (2012). Recent advances in graphene family materials toxicity investigations. J. Nanoparticle Res. 14, 1-21. doi: 10.1007/s11051-012-1320-8

Ji, L., and Zhang, X. (2009). Fabrication of porous carbon nanofibers and their application as anode materials for rechargeable lithium-ion batteries. Nanotechnology 20, 155705. doi: 10.1088/0957-4484/20/15/155705

Jin, H., Chen, W. Q., Tang, X. W., Chiang, L. Y., Yang, C. Y., Schloss, J. V., et al. (2000). Polyhydroxylated C60, fullerenols, as glutamate receptor antagonists and neuroprotective agents. J. Neurosci. Res. 62, 600-607. doi: 10.1002/10974547(20001115)62:4<600::AID-JNR15>3.0.CO;2-F

Jin, G.-Z., Kim, M., Shin, U. S., and Kim, H.-W. (2011). Neurite outgrowth of dorsal root ganglia neurons is enhanced on aligned nanofibrous biopolymer scaffold with carbon nanotube coating. Neurosci. Lett. 501, 10-14. doi: 10.1016/j.neulet.2011.06.023

Johnston, H. J., Hutchison, G. R., Christensen, F. M., Aschberger, K., and Stone, V. (2010). The biological mechanisms and physicochemical characteristics responsible for driving fullerene toxicity. Toxicol. Sci. 114, 162-182. doi: $10.1093 /$ toxsci/kfp265

Kafa, H., Wang, J. T.-W., Rubio, N., Venner, K., Anderson, G., Pach, E., et al. (2015). The interaction of carbon nanotubes with an in vitro bloodbrain barrier model and mouse brain in vivo. Biomaterials 53, 437-452. doi: 10.1016/j.biomaterials.2015.02.083

Kagan, V. E., Kapralov, A. A., St. Croix, C. M., Watkins, S. C., Kisin, E. R., Kotchey, G. P., et al. (2014). Lung macrophages "Digest" carbon nanotubes using a superoxide/peroxynitrite oxidative pathway. ACS Nano 8, 5610-5621. doi: $10.1021 / \mathrm{nn} 406484 \mathrm{~b}$

Kam, N. W. S., Jan, E., and Kotov, N. A. (2009). Electrical stimulation of neural stem cells mediated by humanized carbon nanotube composite made with extracellular matrix protein. Nano Lett. 9, 273-278. doi: 10.1021/nl802859a

Kanakia, S., Toussaint, J. D., Mullick Chowdhury, S., Tembulkar, T., Lee, S., Jiang, Y.-P., et al. (2014). Dose ranging, expanded acute toxicity and safety pharmacology studies for intravenously administered functionalized graphene nanoparticle formulations. Biomaterials 35, 7022-7031. doi: 10.1016/j.biomaterials.2014.04.066

Kateb, B., Van Handel, M., Zhang, L., Bronikowski, M. J., Manohara, H., and Badie, B. (2007). Internalization of MWCNTs by microglia: possible application in immunotherapy of brain tumors. Neuroimage 37, S9-S17. doi: 10.1016/j.neuroimage.2007.03.078

Keefer, E. W., Botterman, B. R., Romero, M. I., Rossi, A. F., and Gross, G. W. (2008). Carbon nanotube coating improves neuronal recordings. Nat. Nanotechnol. 3, 434-439. doi: 10.1038/nnano.2008.174

Kim, H., Namgung, R., Singha, K., Oh, I.-K., and Kim, W. J. (2011). Graphene oxide-polyethylenimine nanoconstruct as a gene delivery vector and bioimaging tool. Bioconjug. Chem. 22, 2558-2567. doi: 10.1021/bc200397j

Kirner, S., Sekita, M., and Guldi, D. M. (2014). 25th anniversary article: 25 years of fullerene research in electron transfer chemistry. Adv. Mater. 26, 1482-1493. doi: 10.1002/adma.201304928

Klein, K. L., Melechko, A. V., McKnight, T. E., Retterer, S. T., Rack, P. D., Fowlkes, J. D., et al. (2008). Surface characterization and functionalization of carbon nanofibers. J. Appl. Phys. 103, 061301. doi: 10.1063/1.2840049

Kolosnjaj, J., Szwarc, H., and Moussa, F. (2007). “Toxicity studies of fullerenes and derivatives," in Advances in Experimental Medicine and Biology, Vol. 620, ed W. C. W. Chan (New York, NY: Springer New York), 168-180.

Kosaka, M., Kuroshima, S., Kobayashi, K., Sekino, S., Ichihashi, T., Nakamura, S., et al. (2009). Single-wall carbon nanohorns supporting pt catalyst in direct methanol fuel cells. J. Phys. Chem. C 113, 8660-8667. doi: 10.1021/jp8105293

Kotchey, G. P., Hasan, S., a., Kapralov, A., a., Ha, S. H., Kim, K., Shvedova, A., et al. (2012). A natural vanishing act: the enzyme-catalyzed degradation of carbon nanomaterials. Acc. Chem. Res. 45, 1770-1781. doi: 10.1021/ar300106h

Kotchey, G. P., Zhao, Y., Kagan, V. E., and Star, A. (2013). Peroxidase-mediated biodegradation of carbon nanotubes in vitro and in vivo. Adv. Drug Deliv. Rev. 65, 1921-1932. doi: 10.1016/j.addr.2013.07.007

Ladeira, M. S., Andrade, V. A, Gomes, E. R. M., Aguiar, C. J., Moraes, E. R., Soares, J. S., et al. (2010). Highly efficient siRNA delivery system into human and murine cells using single-wall carbon nanotubes. Nanotechnology 21, 385101. doi: 10.1088/0957-4484/21/38/385101

Lai, C.-W., Hsiao, Y.-H., Peng, Y.-K., and Chou, P.-T. (2012). Facile synthesis of highly emissive carbon dots from pyrolysis of glycerol; gram scale production of carbon dots $/ \mathrm{mSiO} 2$ for cell imaging and drug release. J. Mater. Chem. 22, 14403. doi: 10.1039/c2jm32206d

Lalwani, G., Cai, X., Nie, L., Wang, L. V., and Sitharaman, B. (2013). Graphenebased contrast agents for photoacoustic and thermoacoustic tomography. Photoacoustics 1, 62-67. doi: 10.1016/j.pacs.2013.10.001

Lamberti, M., Pedata, P., Sannolo, N., Porto, S., De Rosa, A., and Caraglia, M. (2015). Carbon nanotubes: properties, biomedical applications, advantages and risks in patients and occupationally-exposed workers. Int. J. Immunopathol. Pharmacol. 28, 4-13. doi: 10.1177/0394632015572559

Lee, H. J., Park, J., Yoon, O. J., Kim, H. W., Lee, D. Y., Kim, D. H., et al. (2011). Amine-modified single-walled carbon nanotubes protect neurons from injury in a rat stroke model. Nat. Nanotechnol. 6, 121-125. doi: 10.1038/nnano.2010.281

Lee, W. C., Lim, C. H. Y. X., Shi, H., Tang, L. A. L., Wang, Y., Lim, C. T., et al. (2011). Origin of enhanced stem cell growth and differentiation on graphene and graphene oxide. ACS Nano 5, 7334-7341. doi: 10.1021/nn202190c

Li, Q., Ohulchanskyy, T. Y., Liu, R., Koynov, K., Wu, D., Best, A., et al. (2010). Photoluminescent carbon dots as biocompatible nanoprobes for targeting cancer cells in vitro. J. Phys. Chem. C 114, 12062-12068. doi: 10.1021/jp911539r

Li, N., Zhang, X., Song, Q., Su, R., Zhang, Q., Kong, T., et al. (2011). The promotion of neurite sprouting and outgrowth of mouse hippocampal cells in culture by graphene substrates. Biomaterials 32, 9374-9382. doi: 10.1016/j.biomaterials.2011.08.065

Li, J. L., Bao, H. C., Hou, X. L., Sun, L., Wang, X. G., and Gu, M. (2012). Graphene oxide nanoparticles as a nonbleaching optical probe for two-photon luminescence imaging and cell therapy. Angew. Chem. Int. Ed. 51, 1830-1834. doi: 10.1002/anie.201106102

Li, M., Yang, X., Ren, J., Qu, K., and Qu, X. (2012). Using graphene oxide high near-infrared absorbance for photothermal treatment of Alzheimer's disease. Adv. Mater. 24, 1722-1728. doi: 10.1002/adma.201104864

Li, H., Kang, Z., Liu, Y., and Lee, S.-T. (2012). Carbon nanodots: synthesis, properties and applications. J. Mater. Chem. 22, 24230-24253. doi: $10.1039 / \mathrm{c} 2 \mathrm{jm} 34690 \mathrm{~g}$

Li, N., Zhang, Q., Gao, S., Song, Q., Huang, R., Wang, L., et al. (2013). Threedimensional graphene foam as a biocompatible and conductive scaffold for neural stem cells. Sci. Rep. 3, 1604. doi: 10.1038/srep01604 
Li, J., Ying, G.-G., Jones, K. C., and Martin, F. L. (2015). Real-world carbon nanoparticle exposures induce brain and gonadal alterations in zebrafish (Danio rerio) as determined by biospectroscopy techniques. Analyst 140, 2687-2695. doi: 10.1039/C4AN02227K

Li, N., Zhao, Q., Shu, C., Ma, X., Li, R., Shen, H., et al. (2015). Targeted killing of cancer cells in vivo and in vitro with IGF-IR antibody-directed carbon nanohorns based drug delivery. Int. J. Pharm. 478, 644-654. doi: 10.1016/j.ijpharm.2014.12.015

Lim, S. A., and Ahmed, M. U. (2015). A carbon nanofiber-based label free immunosensor for high sensitive detection of recombinant bovine somatotropin. Biosens. Bioelectron. 70, 48-53. doi: 10.1016/j.bios.2015. 03.022

Lim, S. Y., Shen, W., and Gao, Z. (2015). Carbon quantum dots and their applications. Chem. Soc. Rev. 44, 362-381. doi: 10.1039/C4CS00269E

Lin, A. M. Y., Chyi, B. Y., Wang, S. D., Yu, H.-H., Kanakamma, P. P., Luh, T.-Y., et al. (2001). Carboxyfullerene prevents iron-induced oxidative stress in rat brain. J. Neurochem. 72, 1634-1640. doi: 10.1046/j.1471-4159.1999.7 21634.x

Lin, A. M.-Y., Fang, S.-F., Lin, S.-Z., Chou, C.-K., Luh, T.-Y., and Ho, L.-T. (2002). Local carboxyfullerene protects cortical infarction in rat brain. Neurosci. Res. 43, 317-321. doi: 10.1016/S0168-0102(02)00056-1

Liu, H., Ye, T., and Mao, C. (2007). Fluorescent carbon nanoparticles derived from candle soot. Angew. Chem. Int. Ed. 46, 6473-6475. doi: 10.1002/anie.200701271

Liu, K.-K., Chen, M.-F., Chen, P.-Y., Lee, T. J. F., Cheng, C.-L., Chang, C.C., et al. (2008). Alpha-bungarotoxin binding to target cell in a developing visual system by carboxylated nanodiamond. Nanotechnology 19, 205102. doi: $10.1088 / 0957-4484 / 19 / 20 / 205102$

Liu, Z., Tabakman, S., Welsher, K., and Dai, H. (2009). Carbon nanotubes in biology and medicine: in vitro and in vivo detection, imaging and drug delivery. Nano Res. 2, 85-120. doi: 10.1007/s12274-009-9009-8

Liu, K.-K., Wang, C.-C., Cheng, C.-L., and Chao, J.-I. (2009). Endocytic carboxylated nanodiamond for the labeling and tracking of cell division and differentiation in cancer and stem cells. Biomaterials 30, 4249-4259. doi: 10.1016/j.biomaterials.2009.04.056

Liu, R., Wu, D., Liu, S., Koynov, K., Knoll, W., and Li, Q. (2009). An aqueous route to multicolor photoluminescent carbon dots using silica spheres as carriers. Angew. Chemie Int. Ed. 48, 4598-4601. doi: 10.1002/anie.200900652

Liu, J.-H., Anilkumar, P., Cao, L., Wang, X., Yang, S.-T., Luo, P. G., et al. (2010). Cytotoxicity evaluations of fluorescent carbon nanoparticles. Nano Life 01, 153-161. doi: 10.1142/S1793984410000158

Liu, Z., Yang, K., and Lee, S.-T. (2011). Single-walled carbon nanotubes in biomedical imaging. J. Mater. Chem. 21, 586-598. doi: 10.1039/C0JM02020F

Liu, C., Zhang, P., Tian, F., Li, W., Li, F., and Liu, W. (2011). One-step synthesis of surface passivated carbon nanodots by microwave assisted pyrolysis for enhanced multicolor photoluminescence and bioimaging. J. Mater. Chem. 21, 13163. doi: $10.1039 / \mathrm{cljm} 12744 \mathrm{f}$

Liu, C., Zhang, P., Zhai, X., Tian, F., Li, W., Yang, J., et al. (2012). Nanocarrier for gene delivery and bioimaging based on carbon dots with PEI-passivation enhanced fluorescence. Biomaterials 33, 3604-3613. doi: 10.1016/j.biomaterials.2012.01.052

Liu, G., Shen, H., Mao, J., Zhang, L., Jiang, Z., Sun, T., et al. (2013). Transferrin modified graphene oxide for glioma-targeted drug delivery: in vitro and in vivo evaluations. ACS Appl. Mater. Interfaces 5, 6909-6914. doi: 10.1021/am402128s

Liu, Q., Guo, B., Rao, Z., Zhang, B., and Gong, J. R. (2013). Strong twophoton-induced fluorescence from photostable, biocompatible nitrogen-doped graphene quantum dots for cellular and deep-tissue imaging. Nano Lett. 13, 2436-2441. doi: 10.1021/nl400368v

Lodermeyer, F., Costa, R. D., Casillas, R., Kohler, F. T. U., Wasserscheid, P., Prato, M., et al. (2015). Carbon nanohorn-based electrolyte for dye-sensitized solar cells. Energy Environ. Sci. 8, 241-246. doi: 10.1039/C4EE02037E

Lovat, V., Pantarotto, D., Lagostena, L., Cacciari, B., Grandolfo, M., Righi, M., et al. (2005). Carbon nanotube substrates boost neuronal electrical signaling. Nano Lett. 5, 1107-1110. doi: 10.1021/nl050637m

Luo, X., Weaver, C. L., Zhou, D. D., Greenberg, R., and Cui, X. T. (2011). Highly stable carbon nanotube doped poly(3,4-ethylenedioxythiophene) for chronic neural stimulation. Biomaterials 32, 5551-5557. doi: 10.1016/j.biomaterials.2011.04.051
Luo, P. G., Sahu, S., Yang, S.-T., Sonkar, S. K., Wang, J., Wang, H., et al. (2013). Carbon "quantum" dots for optical bioimaging. J. Mater. Chem. B 1, 2116. doi: $10.1039 / \mathrm{c} 3 \mathrm{tb} 00018 \mathrm{~d}$

Lynch, R. M., Voy, B. H., Glass, D. F., Mahurin, S. M., Zhao, B., Hu, H., et al. (2007). Assessing the pulmonary toxicity of single-walled carbon nanohorns. Nanotoxicology 1, 157-166. doi: 10.1080/17435390701598496

Ma, X., Shu, C., Guo, J., Pang, L., Su, L., Fu, D., et al. (2014). Targeted cancer therapy based on single-wall carbon nanohorns with doxorubicin in vitro and in vivo. J. Nanoparticle Res. 16, 2497. doi: 10.1007/s11051-014-2497-9

Magrez, A., Kasas, S., Salicio, V., Pasquier, N., Seo, J. W., Celio, M., et al. (2006). Cellular toxicity of carbon-based nanomaterials. Nano Lett. 6, 1121-1125. doi: $10.1021 / \mathrm{nl} 060162 \mathrm{e}$

Matija, L., Tsenkova, R., Munćan, J., Miyazaki, M., Banba, K., Tomić, M., et al. (2013). Fullerene based nanomaterials for biomedical applications: engineering, functionalization and characterization. Adv. Mater. Res. 633, 224-238. doi: 10.4028/www.scientific.net/AMR.633.224

Mattson, M. P., Haddon, R. C., and Rao, A. M. (2000). Molecular functionalization of carbon nanotubes and use as substrates for neuronal growth. J. Mol. Neurosci. 14, 175-182. doi: 10.1385/JMN:14:3:175

Mazzatenta, A., Giugliano, M., Campidelli, S., Gambazzi, L., Businaro, L., Markram, H., et al. (2007). Interfacing neurons with carbon nanotubes: electrical signal transfer and synaptic stimulation in cultured brain circuits. J. Neurosci. 27, 6931-6936. doi: 10.1523/JNEUROSCI.1051-07.2007

McKnight, T. E., Melechko, A. V., Griffin, G. D., Guillorn, M., a, Merkulov, V. I., Serna, F., et al. (2003). Intracellular integration of synthetic nanostructures with viable cells for controlled biochemical manipulation. Nanotechnology 14 , 551-556. doi: 10.1088/0957-4484/14/5/313

McKnight, T. E., Melechko, A. V., Fletcher, B. L., Jones, S. W., Hensley, D. K., Peckys, D. B., et al. (2006). Resident neuroelectrochemical interfacing using carbon nanofiber arrays. J. Phys. Chem. B 110, 15317-15327. doi: $10.1021 / \mathrm{jp} 056467 \mathrm{j}$

Mintmire, J. W., and White, C. T. (1995). Electronic and structural properties of carbon nanotubes. Carbon 33, 893-902. doi: 10.1016/0008-6223(95)00018-9

Miyawaki, J., Yudasaka, M., Imai, H., Yorimitsu, H., Isobe, H., Nakamura, E., et al. (2006). In vivo magnetic resonance imaging of single-walled carbon nanohorns by labeling with magnetite nanoparticles. Adv. Mater. 18, 1010-1014. doi: 10.1002/adma.200502174

Miyawaki, J., Yudasaka, M., Azami, T., Kubo, Y., and Iijima, S. (2008). Toxicity of single-walled carbon nanohorns. ACS Nano 2, 213-226. doi: $10.1021 / \mathrm{nn} 700185 \mathrm{t}$

Miyawaki, J., Matsumura, S., Yuge, R., Murakami, T., Sato, S., Tomida, A., et al. (2009). Biodistribution and ultrastructural localization of single-walled carbon nanohorns determined in vivo with embedded $\mathrm{Gd}_{2} \mathrm{O}_{3}$ labels. ACS Nano 3, 1399-1406. doi: 10.1021/nn9004846

Mochalin, V. N., Shenderova, O., Ho, D., and Gogotsi, Y. (2011). The properties and applications of nanodiamonds. Nat. Nanotechnol. 7, 11-23. doi: 10.1038/nnano.2011.209

Monaco, A. M., and Giugliano, M. (2014). Carbon-based smart nanomaterials in biomedicine and neuroengineering. Beilstein J. Nanotechnol. 5, 1849-1863. doi: 10.3762/bjnano.5.196

Moon, S. U., Kim, J., Bokara, K. K., Kim, J. Y., Khang, D., Webster, T. J., et al. (2012). Carbon nanotubes impregnated with subventricular zone neural progenitor cells promotes recovery from stroke. Int. J. Nanomed. 7, 2751-2765. doi: $10.2147 /$ IJN.S30273

Mouchet, F., Landois, P., Sarremejean, E., Bernard, G., Puech, P., Pinelli, E., et al. (2008). Characterisation and in vivo ecotoxicity evaluation of double-wall carbon nanotubes in larvae of the amphibian Xenopus laevis. Aquat. Toxicol. 87, 127-137. doi: 10.1016/j.aquatox.2008.01.011

Movia, D., Prina-Mello, A., Bazou, D., Volkov, Y., and Giordani, S. (2011). Screening the cytotoxicity of single-walled carbon nanotubes using novel 3D tissue-mimetic models. ACS Nano 5, 9278-9290. doi: 10.1021/nn203659m

Movia, D., and Giordani, S. (2012). "Toxicity of carbon nanotubes," in Handbook of Green Chemistry, eds A. Perosa and M. Selva (Weinheim: Wiley - VCH), 175-216.

Muller, J., Huaux, F., Moreau, N., Misson, P., Heilier, J.-F., Delos, M., et al. (2005). Respiratory toxicity of multi-wall carbon nanotubes. Toxicol. Appl. Pharmacol. 207, 221-231. doi: 10.1016/j.taap.2005.01.008 
Murakami, T., Ajima, K., Miyawaki, J., Yudasaka, M., Iijima, S., and Shiba, K. (2004). Drug-loaded carbon nanohorns: adsorption and release of dexamethasone in vitro. Mol. Pharm. 1, 399-405. doi: 10.1021/mp04 $9928 \mathrm{e}$

Nakazono, M., Hasegawa, S., Yamamoto, T., and Zaitsu, K. (2004). Synthesis of 61-bis(1-adamantylcarbamoyl)-1,2-methano[60]fullerene and its antagonistic effect on haloperidol-induced catalepsy in mice. Bioorg. Med. Chem. Lett. 14, 5619-5621. doi: 10.1016/j.bmcl.2004.08.053

Nguyen-Vu, T. D. B., Chen, H., Cassell, A. M., Andrews, R. J., Meyyappan, M., and Li, J. (2007). Vertically aligned carbon nanofiber architecture as a multifunctional 3-D neural electrical interface. IEEE Trans. Biomed. Eng. 54, 1121-1128. doi: 10.1109/TBME.2007.891169

Nunes, A., Bussy, C., Gherardini, L., Meneghetti, M., Herrero, M. A., Bianco, A., et al. (2012). In vivo degradation of functionalized carbon nanotubes after stereotactic administration in the brain cortex. Nanomedicine 7, 1485-1494. doi: $10.2217 / \mathrm{nnm} .12 .33$

Odom, T. W., Huang, J., Kim, P., and Lieber, C. M. (2000). Structure and electronic properties of carbon nanotubes. J. Phys. Chem. B 104, 2794-2809. doi: $10.1021 /$ jp993592k

Pagona, G., Fan, J., Maignè, A., Yudasaka, M., Iijima, S., and Tagmatarchis, N. (2007). Aqueous carbon nanohorn-pyrene-porphyrin nanoensembles: controlling charge-transfer interactions. Diam. Relat. Mater. 16, 1150-1153. doi: 10.1016/j.diamond.2006.11.071

Park, S. Y., Choi, D. S., Jin, H. J., Park, J., Byun, K.-E., Lee, K.-B., et al. (2011a). Polarization-controlled differentiation of human neural stem cells using synergistic cues from the patterns of carbon nanotube monolayer coating. ACS Nano 5, 4704-4711. doi: 10.1021/nn2006128

Park, S. Y., Park, J., Sim, S. H., Sung, M. G., Kim, K. S., Hong, B. H., et al. (2011b). Enhanced differentiation of human neural stem cells into neurons on graphene. Adv. Mater. 23, H263-H267. doi: 10.1002/adma.201101503

Park, D.-W., Schendel, A. A., Mikael, S., Brodnick, S. K., Richner, T. J., Ness, J. P., et al. (2014). Graphene-based carbon-layered electrode array technology for neural imaging and optogenetic applications. Nat. Commun. 5, 5258. doi: $10.1038 /$ ncomms 6258

Partha, R., and Conyers, J. L. (2009). Biomedical applications of functionalized fullerene-based nanomaterials. Int. J. Nanomed. 4, 261-275. doi: $10.2147 /$ IJN.S5964

Peng, C., Hu, W., Zhou, Y., Fan, C., and Huang, Q. (2010). Intracellular imaging with a graphene-based fluorescent probe. Small 6, 1686-1692. doi: $10.1002 / \mathrm{smll} .201000560$

Perevedentseva, E., Lin, Y.-C., Jani, M., and Cheng, C.-L. (2013). Biomedical applications of nanodiamonds in imaging and therapy. Nanomedicine 8, 2041-2060. doi: 10.2217/nnm.13.183

Podolski, I. Y., Kondratjeva, E. V., Gurin, S. S., Dumpis, M. A., and Piotrovsky, L. B. (2005). Fullerene C 60 complexed with Poly(N-Vinyl-pyrrolidone) (C 60 /PVP) prevents the disturbance of long-term memory consolidation induced by cycloheximide. Fullerenes Nanotub. Carbon Nanostruct. 12, 421-424. doi: 10.1081/FST-120027201

Podolski, I. Y., Podlubnaya, Z. A, Kosenko, E. A, Mugantseva, E. A, Makarova, E. G., Marsagishvili, L. G., et al. (2007). Effects of hydrated forms of $\mathrm{C}_{60}$ fullerene on amyloid $\beta$ peptide fibrillization in vitro and performance of the cognitive task. J. Nanosci. Nanotechnol. 7, 1479-1485. doi: 10.1166/jnn.2007.330

Poland, C. A, Duffin, R., Kinloch, I., Maynard, A., Wallace, W. A, H., et al. (2008). Carbon nanotubes introduced into the abdominal cavity of mice show asbestos-like pathogenicity in a pilot study. Nat. Nanotechnol. 3, 423-428. doi: 10.1038/nnano.2008.111

Popov, V. (2004). Carbon nanotubes: properties and application. Mater. Sci. Eng. $R$ Reports 43, 61-102. doi: 10.1016/j.mser.2003.10.001

Pulskamp, K., Diabaté, S., and Krug, H. F. (2007). Carbon nanotubes show no sign of acute toxicity but induce intracellular reactive oxygen species in dependence on contaminants. Toxicol. Lett. 168, 58-74. doi: 10.1016/j.toxlet.2006.11.001

Qian, J., Wang, D., Cai, F.-H., Xi, W., Peng, L., Zhu, Z.-F., et al. (2012). Observation of multiphoton-induced fluorescence from graphene oxide nanoparticles and applications in in vivo functional bioimaging. Angew. Chemie Int. Ed. 51, 10570-10575. doi: 10.1002/anie.201206107

Qian, J., Ruan, S., Cao, X., Cun, X., Chen, J., Shen, S., et al. (2014). Fluorescent carbonaceous nanospheres as biological probe for noninvasive brain imaging. J. Colloid Interface Sci. 436, 227-233. doi: 10.1016/j.jcis.2014.08.059
Qiao, Z.-A., Wang, Y., Gao, Y., Li, H., Dai, T., Liu, Y., et al. (2010). Commercially activated carbon as the source for producing multicolor photoluminescent carbon dots by chemical oxidation. Chem. Commun. 46, 8812. doi: $10.1039 / \mathrm{c} 0 \mathrm{cc} 02724 \mathrm{c}$

Qu, S., Wang, X., Lu, Q., Liu, X., and Wang, L. (2012). A biocompatible fluorescent ink based on water-soluble luminescent carbon nanodots. Angew. Chemie Int. Ed. 51, 12215-12218. doi: 10.1002/anie.201206791

Qu, G., Wang, X., Liu, Q., Liu, R., Yin, N., Ma, J., et al. (2013). The ex vivo and in vivo biological performances of graphene oxide and the impact of surfactant on graphene oxide's biocompatibility. J. Environ. Sci. 25, 873-881. doi: 10.1016/S1001-0742(12)60252-6

Quick, K. L., Ali, S. S., Arch, R., Xiong, C., Wozniak, D., and Dugan, L. L. (2008). A carboxyfullerene SOD mimetic improves cognition and extends the lifespan of mice. Neurobiol. Aging 29, 117-128. doi: 10.1016/j.neurobiolaging.2006.09.014

Ramos, A., Cameán, I., and García, A. B. (2013). Graphitization thermal treatment of carbon nanofibers. Carbon 59, 2-32. doi: 10.1016/j.carbon.2013.03.031

Rand, E., Periyakaruppan, A., Tanaka, Z., Zhang, D. A., Marsh, M. P., Andrews, R. J., et al. (2013). A carbon nanofiber based biosensor for simultaneous detection of dopamine and serotonin in the presence of ascorbicacid. Biosens. Bioelectron. 42, 434-438. doi: 10.1016/j.bios.2012.10.080

Ren, J., Shen, S., Wang, D., Xi, Z., Guo, L., Pang, Z., et al. (2012). The targeted delivery of anticancer drugs to brain glioma by PEGylated oxidized multi-walled carbon nanotubes modified with angiopep-2. Biomaterials 33, 3324-3333. doi: 10.1016/j.biomaterials.2012.01.025

Robinson, J. T., Tabakman, S. M., Liang, Y., Wang, H., Sanchez Casalongue, H., Vinh, D., et al. (2011). Ultrasmall reduced graphene oxide with high near-infrared absorbance for photothermal therapy. J. Am. Chem. Soc. 133, 6825-6831. doi: 10.1021/ja2010175

Rodriguez, N. M., Kim, M.-S., and Baker, R. T. K. (1994). Carbon Nanofibers: a unique catalyst support medium. J. Phys. Chem. 98, 13108-13111. doi: 10.1021/j100101a003

Rojas, S., Gispert, J. D., Martín, R., Abad, S., Menchón, C., Pareto, D. R., et al. (2011). Biodistribution of Amino-functionalized diamond nanoparticles in vivo studies based on 18 F radionuclide emission. ACS Nano 5, 5552-5559. doi: $10.1021 / \mathrm{nn} 200986 \mathrm{z}$

Roman, J. A., Niedzielko, T. L., Haddon, R. C., Parpura, V., and Floyd, C. L. (2011). Single-walled carbon nanotubes chemically functionalized with polyethylene glycol promote tissue repair in a rat model of spinal cord injury. J. Neurotrauma 28, 2349-2362. doi: 10.1089/neu.2010.1409

Ruan, S., Qian, J., Shen, S., Zhu, J., Jiang, X., He, Q., et al. (2014). A simple one-step method to prepare fluorescent carbon dots and their potential application in non-invasive glioma imaging. Nanoscale 6, 10040. doi: 10.1039/C4NR02657H

Ruoff, R. S., and Lorents, D. C. (1995). Mechanical and thermal properties of carbon nanotubes. Carbon 33, 925-930. doi: 10.1016/0008-6223(95)00021-5

Salvetat, J.-P., Bonard, J.-M., Thomson, N. H., Kulik, A. J., Forrand, L., Benoit, W., et al. (1999). Mechanical properties of carbon nanotubes. Appl. Phys. A Mater. Sci. Process. 69, 255-260. doi: 10.1007/s003390050999

Sano, N., Taniguchi, K., and Tamon, H. (2014). Hydrogen storage in porous singlewalled carbon nanohorns dispersed with $\mathrm{Pd}-\mathrm{Ni}$ alloy nanoparticles. J. Phys. Chem. C 118, 3402-3408. doi: 10.1021/jp4098155

Sato, Y., Shibata, K., Kataoka, H., Ogino, S., Bunshi, F., Yokoyama, A., et al. (2005). Strict preparation and evaluation of water-soluble hat-stacked carbon nanofibers for biomedical application and their high biocompatibility: influence of nanofiber-surface functional groups on cytotoxicity. Mol. Biosyst. 1, 142. doi: 10.1039/b501222h

Schrand, A. M., Dai, L., Schlager, J. J., Hussain, S. M., and Osawa, E. (2007a). Differential biocompatibility of carbon nanotubes and nanodiamonds. Diam. Relat. Mater. 16, 2118-2123. doi: 10.1016/j.diamond.2007. 07.020

Schrand, A. M., Huang, H., Carlson, C., Schlager, J. J., Ōsawa, E., Hussain, S. M., et al. (2007b). Are diamond nanoparticles cytotoxic? J. Phys. Chem. B 111, 2-7. doi: $10.1021 /$ jp066387y

Schrand, A., Hens, S.,A., C., and Shenderova, O. (2009). Nanodiamond Particles: properties and perspectives for bioapplications. Crit. Rev. Solid State Mater. Sci. 34, 18-74. doi: 10.1080/10408430902831987

Seabra, A. B., Paula, A. J., de Lima, R., Alves, O. L., and Durán, N. (2014). Nanotoxicity of graphene and graphene oxide. Chem. Res. Toxicol. 27, 159-168. doi: $10.1021 /$ tx $400385 \mathrm{x}$ 
Sergio, M., Behzadi, H., Otto, A., and van der Spoel, D. (2013). Fullerenes toxicity and electronic properties. Environ. Chem. Lett. 11, 105-118. doi: 10.1007/s10311-012-0387-x

Serrano, M. C., Patiño, J., García-Rama, C., Ferrer, M. L., Fierro, J. L. G., Tamayo, A., et al. (2014). 3D free-standing porous scaffolds made of graphene oxide as substrates for neural cell growth. J. Mater. Chem. B 2, 5698. doi: 10.1039/C4TB00652F

Sharifi, S., Behzadi, S., Laurent, S., Laird Forrest, M., Stroeve, P., and Mahmoudi, M. (2012). Toxicity of nanomaterials. Chem. Soc. Rev. 41, 2323-2343. doi: 10.1039/C1CS15188F

Shein, M., Greenbaum, A., Gabay, T., Sorkin, R., David-Pur, M., Ben-Jacob, E., et al. (2009). Engineered neuronal circuits shaped and interfaced with carbon nanotube microelectrode arrays. Biomed. Microdevices 11, 495-501. doi: 10.1007/s10544-008-9255-7

Shen, J., Zhu, Y., Yang, X., and Li, C. (2012). Graphene quantum dots: emergent nanolights for bioimaging, sensors, catalysis and photovoltaic devices. Chem. Commun. 48, 3686. doi: 10.1039/c2cc00110a

Shen, J., Li, Y., Su, Y., Zhu, Y., Jiang, H., Yang, X., et al. (2015). Photoluminescent carbon-nitrogen quantum dots as efficient electrocatalysts for oxygen reduction. Nanoscale 7, 2003-2008. doi: 10.1039/C4NR06484D

Sherigara, B. S., Kutner, W., and D'Souza, F. (2003). Electrocatalytic properties and sensor applications of fullerenes and carbon nanotubes. Electroanalysis 15, 753-772. doi: 10.1002/elan.200390094

Shevtsov, M.A., Nikolaev, B. P., Marchenko, Y. Y., Yakovleva, L. Y., Dobrodumova, V., Török, G., et al., (2014). Magnetic resonance imaging of rat C6 glioma model enhanced by using water-soluble gadolinium fullerene. Appl. Magn. Reson. 45, 303-314. doi: 10.1007/s00723-014-0519-5

Shoval, A. (2009). Carbon nanotube electrodes for effective interfacing with retinal tissue. Front. Neuroeng. 2:4. doi: 10.3389/neuro.16.004.2009

Smith, C. J., Shaw, B. J., and Handy, R. D. (2007). Toxicity of single walled carbon nanotubes to rainbow trout, (Oncorhynchus mykiss): respiratory toxicity, organ pathologies, and other physiological effects. Aquat. Toxicol. 82, 94-109. doi: 10.1016/j.aquatox.2007.02.003

Sohaebuddin, S. K., Thevenot, P. T., Baker, D., Eaton, J. W., and Tang, L. (2010). Nanomaterial cytotoxicity is composition, size, and cell type dependent. Part. Fibre Toxicol. 7:22. doi: 10.1186/1743-8977-7-22

Song, Q., Jiang, Z., Li, N., Liu, P., Liu, L., Tang, M., et al. (2014). Anti-inflammatory effects of three-dimensional graphene foams cultured with microglial cells. Biomaterials 35, 6930-6940. doi: 10.1016/j.biomaterials.2014.05.002

Sonkar, S. K., Ghosh, M., Roy, M., Begum, A., and Sarkar, S. (2012). Carbon nanoonions as nontoxic and high-fluorescence bioimaging agent in food chain-an in vivo study from unicellular E. coli to multicellular C. elegans. Mater. Express 2, 105-114. doi: 10.1166/mex.2012.1064

Strauss, V., Margraf, J. T., Dolle, C., Butz, B., Nacken, T. J., Walter, J., et al. (2014). Carbon Nanodots: toward a comprehensive understanding of their photoluminescence. J. Am. Chem. Soc. 136, 17308-17316. doi: $10.1021 /$ ja510183c

Sun, Y. P., Zhou, B., Lin, Y., Wang, W., Fernando, K. A. S., Pathak, P., et al. (2006). Quantum-sized carbon dots for bright and colorful photoluminescence. J. Am. Chem. Soc. 128, 7756-7757. doi: 10.1021/ja062677d

Sureshbabu, A. R., Kurapati, R., Russier, J., Ménard-Moyon, C., Bartolini, I., Meneghetti, M., et al. (2015). Degradation-by-design: surface modification with functional substrates that enhance the enzymatic degradation of carbon nanotubes. Biomaterials 72, 20-28. doi: 10.1016/j.biomaterials.2015. 08.046

Tagmatarchis, N., Maigné, A., Yudasaka, M., and Iijima, S. (2006). Functionalization of carbon nanohorns with azomethine ylides: towards solubility enhancement and electron-transfer processes. Small 2, 490-494. doi: 10.1002/smll.200500393

Tahara, Y., Miyawaki, J., Zhang, M., Yang, M., Waga, I., Iijima, S., et al. (2011). Histological assessments for toxicity and functionalization-dependent biodistribution of carbon nanohorns. Nanotechnology 22:265106. doi: 10.1088/0957-4484/22/26/265106

Tang, M., Song, Q., Li, N., Jiang, Z., Huang, R., and Cheng, G. (2013). Enhancement of electrical signaling in neural networks on graphene films. Biomaterials 34, 6402-6411. doi: 10.1016/j.biomaterials.2013.05.024

Tao, H., Yang, K., Ma, Z., Wan, J., Zhang, Y., Kang, Z., et al. (2012). In vivo NIR fluorescence imaging, biodistribution, and toxicology of photoluminescent carbon dots produced from carbon nanotubes and graphite. Small 8, 281-290. doi: 10.1002/smll.201101706

Tasis, D., Tagmatarchis, N., Bianco, A., and Prato, M. (2006). Chemistry of carbon nanotubes. Chem. Rev. 106, 1105-1136. doi: 10.1021/cr050569o

Tay, C. Y., Cai, P., Setyawati, M. I., Fang, W., Tan, L. P., Hong, C. H. L., et al. (2014). Nanoparticles strengthen intracellular tension and retard cellular migration. Nano Lett. 14, 83-88. doi: 10.1021/nl4032549

Thalhammer, A., Edgington, R. J., Cingolani, L. A., Schoepfer, R., and Jackman, R. B. (2010). The use of nanodiamond monolayer coatings to promote the formation of functional neuronal networks. Biomaterials 31, 2097-2104. doi: 10.1016/j.biomaterials.2009.11.109

Tokuyama, H., Yamago, S., Nakamura, E., Shiraki, T., and Sugiura, Y. (1993). Photoinduced biochemical activity of fullerene carboxylic acid. J. Am. Chem. Soc. 115, 7918-7919. doi: 10.1021/ja00070a064

Tran, P. A., Zhang, L., and Webster, T. J. (2009). Carbon nanofibers and carbon nanotubes in regenerative medicine. Adv. Drug Deliv. Rev. 61, 1097-1114. doi: 10.1016/j.addr.2009.07.010

Trpkovic, A., Todorovic-Markovic, B., and Trajkovic, V. (2012). Toxicity of pristine versus functionalized fullerenes: mechanisms of cell damage and the role of oxidative stress. Arch. Toxicol. 86, 1809-1827. doi: 10.1007/s00204-0120859-6

Tsao, N., Kanakamma, P. P., Luh, T. Y., Chou, C. K., and Lei, H. Y. (1999). Inhibition of Escherichia coli-induced meningitis by carboxyfullerence. Antimicrob. Agents Chemother. 43, 2273-2277.

Tu, Q., Pang, L., Chen, Y., Zhang, Y., Zhang, R., Lu, B., et al. (2014). Effects of surface charges of graphene oxide on neuronal outgrowth and branching. Analyst 139, 105-115. doi: 10.1039/C3AN01796F

Tykhomyrov, A. A., Nedzvetsky, V. S., Klochkov, V. K., and Andrievsky, G. V. (2008). Nanostructures of hydrated C60 fullerene (C60HyFn) protect rat brain against alcohol impact and attenuate behavioral impairments of alcoholized animals. Toxicology 246, 158-165. doi: 10.1016/j.tox.2008.01.005

Vaijayanthimala, V., and Chang, H.-C. (2009). Functionalized fluorescent nanodiamonds for biomedical applications. Nanomedicine 4, 47-55. doi: 10.2217/17435889.4.1.47

Vaijayanthimala, V., Cheng, P.-Y., Yeh, S.-H., Liu, K.-K., Hsiao, C.-H., Chao, J.I., et al. (2012). The long-term stability and biocompatibility of fluorescent nanodiamond as an in vivo contrast agent. Biomaterials 33, 7794-7802. doi: 10.1016/j.biomaterials.2012.06.084

Valentini, F., Ciambella, E., Conte, V., Sabatini, L., Ditaranto, N., Cataldo, F., et al. (2014). Highly selective detection of Epinephrine at oxidized SingleWall Carbon Nanohorns modified Screen Printed Electrodes (SPEs). Biosens. Bioelectron. 59, 94-98. doi: 10.1016/j.bios.2014.02.065

Vitale, F., Summerson, S. R., Aazhang, B., Kemere, C., and Pasquali, M. (2015). Neural stimulation and recording with bidirectional, soft carbon nanotube fiber microelectrodes. ACS Nano 9, 4465-4474. doi: 10.1021/acsnano.5 b01060

Vittorio, O., Raffa, V., and Cuschieri, A. (2009). Influence of purity and surface oxidation on cytotoxicity of multiwalled carbon nanotubes with human neuroblastoma cells. Nanomed. Nanotechnol. Biol. Med. 5, 424-431. doi: 10.1016/j.nano.2009.02.006

Vizuete, M., Gómez-Escalonilla, M. J., Fierro, J. L. G., Sandanayaka, A. S. D., Hasobe, T., Yudasaka, M., et al. (2010). A carbon nanohorn-porphyrin supramolecular assembly for photoinduced electron-transfer processes. Chem. A Eur. J. 16, 10752-10763. doi: 10.1002/chem.201000299

Voiry, D., Pagona, G., Canto, E., Del Ortolani, L., Noé, L., Morandi, V., et al. (2015). Reductive dismantling and functionalization of carbon nanohorns. Chem. Commun. 51, 5017-5019. doi: 10.1039/C4CC10389K

Vorobyov, V., Kaptsov, V., Gordon, R., Makarova, E., Podolski, I., and Sengpiel, F. (2015). Neuroprotective effects of hydrated fullerene C60: cortical and hippocampal EEG interplay in an amyloid-infused rat model of Alzheimer's disease. J. Alzheimers. Dis. 45, 217-233. doi: 10.3233/JAD-142469

Wang, J., and Lin, Y. (2008). Functionalized carbon nanotubes and nanofibers for biosensing applications. Trends Anal. Chem. 27, 619-626. doi: 10.1016/j.trac.2008.05.009

Wang, C.-H., Huang, Y.-J., and Peng, C.-A. (2009). "Photothermal ablation of stem-cell like glioblastoma using carbon nanotubes functionalized with antiCD133," in 13th International Conference on Biomedical Engineering, (Berlin: Heidelberg: Springer Berlin Heidelberg), 888-891. 
Wang, K., Wang, Y., Wang, Y., Hosono, E., and Zhou, H. (2009). Mesoporous carbon nanofibers for supercapacitor application. J. Phys. Chem. C 113, 1093-1097. doi: 10.1021/jp807463u

Wang, K., Ruan, J., Song, H., Zhang, J., Wo, Y., Guo, S., et al. (2010). Biocompatibility of graphene oxide. Nanoscale Res. Lett. 6, 1-8. doi: 10.1007/s11671-010-9751-6

Wang, Y., Anilkumar, P., Cao, L., Liu, J.-H., Luo, P. G., Tackett, K. N., et al. (2011). Carbon dots of different composition and surface functionalization: cytotoxicity issues relevant to fluorescence cell imaging. Exp. Biol. Med. 236, 1231-1238. doi: 10.1258/ebm.2011.011132

Wang, F., Xie, Z., Zhang, H., Liu, C., and Zhang, Y. (2011). Highly luminescent organosilane-functionalized carbon dots. Adv. Funct. Mater. 21, 1027-1031. doi: 10.1002/adfm.201002279

Wang, Y., Lee, W. C., Manga, K. K., Ang, P. K., Lu, J., Liu, Y. P., et al. (2012). Fluorinated graphene for promoting neuro-induction of stem cells. Adv. Mater. 24, 4285-4290. doi: 10.1002/adma.201200846

Webster, T. J., Waid, M. C., McKenzie, J. L., Price, R. L., and Ejiofor, J. U. (2004). Nano-biotechnology: carbon nanofibres as improved neural and orthopaedic implants. Nanotechnology 15, 48-54. doi: 10.1088/0957-4484/ $15 / 1 / 009$

Whitney, J. R., Sarkar, S., Zhang, J., Do, T., Young, T., Manson, M. K., et al. (2011). Single walled carbon nanohorns as photothermal cancer agents. Lasers Surg. Med. 43, 43-51. doi: 10.1002/lsm.21025

Wick, P., Louw-Gaume, A. E., Kucki, M., Krug, H. F., Kostarelos, K., Fadeel, B., et al. (2014). Classification framework for graphene-based materials. Angew. Chemie Int. Ed. 53, 7714-7718. doi: 10.1002/anie.201403335

Wu, H.-C., Chang, X., Liu, L., Zhao, F., and Zhao, Y. (2010). Chemistry of carbon nanotubes in biomedical applications. J. Mater. Chem. 20, 1036-1052. doi: 10.1039/B911099M

Wu, L., Luderer, M., Yang, X., Swain, C., Zhang, H., Nelson, K., et al. (2013). Surface passivation of carbon nanoparticles with branched macromolecules influences near infrared bioimaging. Theranostics 3, 677-686. doi: 10.7150/thn 0.6535

Xi, G., Robinson, E., Mania-Farnell, B., Vanin, E. F., Shim, K.-W., Takao, T., et al. (2014). Convection-enhanced delivery of nanodiamond drug delivery platforms for intracranial tumor treatment. Nanomed. Nanotechnol. Biol. Med. 10, 381-391. doi: 10.1016/j.nano.2013.07.013

Xing, Y., and Dai, L. (2009). Nanodiamonds for nanomedicine. Nanomedicine 4, 207-218. doi: 10.2217/17435889.4.2.207

Xu, X., Ray, R., Gu, Y., Ploehn, H. J., Gearheart, L., Raker, K., et al. a (2004). Electrophoretic analysis and purification of fluorescent single-walled carbon nanotube fragments. J. Am. Chem. Soc. 126, 12736-12737. doi: 10.1021/ja040082h

Yamada, T., Jung, D.-Y., Sawada, R., Matsuoka, A., Nakaoka, R., and Tsuchiya, T. (2008). Effects intracerebral microinjection and intraperitoneal injection of [60]fullerene on brain functions differ in rats. J. Nanosci. Nanotechnol. 8, 3973-3980. doi: 10.1166/jnn.2008.414

Yamada, T., Nakaoka, R., Sawada, R., Matsuoka, A., and Tsuchiya, T. (2010). Effects of intracerebral microinjection of hydroxylated-[60]fullerene on brain monoamine concentrations and locomotor behavior in rats. J. Nanosci. Nanotechnol. 10, 604-611. doi: 10.1166/jnn.2010.1720

Yamago, S., Tokuyama, H., Nakamura, E., Kikuchi, K., Kananishi, S., Sueki, K., et al. (1995). In vivo biological behavior of a water-miscible fullerene: 14C labeling, absorption, distribution, excretion and acute toxicity. Chem. Biol. 2, 385-389. doi: 10.1016/1074-5521(95)90219-8

Yang, C.-M., Noguchi, H., Murata, K., Yudasaka, M., Hashimoto, A., Iijima, S., et al. (2005). Highly ultramicroporous single-walled carbon nanohorn assemblies. Adv. Mater. 17, 866-870. doi: 10.1002/adma.200400712

Yang, S.-T., Guo, W., Lin, Y., Deng, X.-Y., Wang, H.-F., Sun, H.-F., et al. (2007). Biodistribution of pristine single-walled carbon nanotubes in vivo. J. Phys. Chem. C 111, 17761-17764. doi: 10.1021/jp070712c

Yang, S.-T., Wang, X., Jia, G., Gu, Y., Wang, T., Nie, H., et al. (2008). Long-term accumulation and low toxicity of single-walled carbon nanotubes in intravenously exposed mice. Toxicol. Lett. 181, 182-189. doi: 10.1016/j.toxlet.2008.07.020

Yang, S.-T., Cao, L., Luo, P. G., Lu, F., Wang, X., Wang, H., et al. (2009a). Carbon dots for optical imaging in vivo. J. Am. Chem. Soc. 131, 11308-11309. doi: $10.1021 /$ ja904843x
Yang, S.-T., Wang, X., Wang, H., Lu, F., Luo, P. G., Cao, L., et al. (2009b). Carbon dots as nontoxic and high-performance fluorescence imaging agents. J. Phys. Chem. C 113, 18110-18114. doi: 10.1021/jp9085969

Yang, K., Zhang, S., Zhang, G., Sun, X., Lee, S.-T., and Liu, Z. (2010). Graphene in mice: ultrahigh in vivo tumor uptake and efficient photothermal therapy. Nano Lett. 10, 3318-3323. doi: 10.1021/nl100996u

Yang, Z., Zhang, Y., Yang, Y., Sun, L., Han, D., Li, H., et al. (2010). Pharmacological and toxicological target organelles and safe use of singlewalled carbon nanotubes as drug carriers in treating Alzheimer disease. Nanomed. Nanotechnol. Biol. Med. 6, 427-441. doi: 10.1016/j.nano.2009.11.007

Yang, Y., Cui, J., Zheng, M., Hu, C., Tan, S., Xiao, Y., et al. (2012). Onestep synthesis of amino-functionalized fluorescent carbon nanoparticles by hydrothermal carbonization of chitosan. Chem. Commun. 48, 380-382. doi: 10.1039/C1CC15678K

Yang, K., Feng, L., Shi, X., and Liu, Z. (2013a). Nano-graphene in biomedicine: theranostic applications. Chem. Soc. Rev. 42, 530-547. doi: 10.1039/C2CS35342C

Yang, M., Flavin, K., Kopf, I., Radics, G., Hearnden, C. H.A., McManus, G. J., et al. (2013). Functionalization of carbon nanoparticles modulates inflammatory cell recruitment and NLRP3 inflammasome activation. Small 9, 4194-4206. doi: $10.1002 /$ smll.201300481

Yang, H.-W., Hua, M.-Y., Hwang, T.-L., Lin, K.-J., Huang, C.-Y., Tsai, R.-Y., et al. (2013). Non-invasive synergistic treatment of brain tumors by targeted chemotherapeutic delivery and amplified focused ultrasound-hyperthermia using magnetic nanographene oxide. Adv. Mater. 25, 3605-3611. doi: 10.1002/adma.201301046

Yang, K., Li, Y., Tan, X., Peng, R., and Liu, Z. (2013b). Behavior and toxicity of graphene and its functionalized derivatives in biological systems. Small 9, 1492-1503. doi: 10.1002/smll.201201417

Yang, H.-W., Huang, C.-Y., Lin, C.-W., Liu, H.-L., Huang, C.-W., Liao, S.-S., et al. (2014). Gadolinium-functionalized nanographene oxide for combined drug and microRNA delivery and magnetic resonance imaging. Biomaterials 35, 6534-6542. doi: 10.1016/j.biomaterials.2014.04.057

Yang, M., Zhang, M., Tahara, Y., Chechetka, S., Miyako, E., Iijima, S., et al. (2014). Lysosomal membrane permeabilization: carbon nanohorn-induced reactive oxygen species generation and toxicity by this neglected mechanism. Toxicol. Appl. Pharmacol. 280, 117-126. doi: 10.1016/j.taap.2014.07.022

Yang, L., Wang, F., Han, H., Yang, L., Zhang, G., and Fan, Z. (2015). Functionalized graphene oxide as a drug carrier for loading pirfenidone in treatment of subarachnoid hemorrhage. Colloids Surf. B Biointerfaces 129, 21-29. doi: 10.1016/j.colsurfb.2015.03.022

Yoshitake, T., Shimakawa, Y., Kuroshima, S., Kimura, H., Ichihashi, T., Kubo, Y., et al. (2002). Preparation of fine platinum catalyst supported on singlewall carbon nanohorns for fuel cell application. Phys. B Condens. Matter 323, 124-126. doi: 10.1016/S0921-4526(02)00871-2

Yuan, Y., Chen, Y., Liu, J.-H., Wang, H., and Liu, Y. (2009). Biodistribution and fate of nanodiamonds in vivo. Diam. Relat. Mater. 18, 95-100. doi: 10.1016/j.diamond.2008.10.031

Zhang, M., Murakami, T., Ajima, K., Tsuchida, K., Sandanayaka, A. S. D., Ito, O., et al. (2008). Fabrication of $\mathrm{ZnPc} /$ protein nanohorns for double photodynamic and hyperthermic cancer phototherapy. Proc. Natl. Acad. Sci. 105, 14773-14778. doi: 10.1073/pnas.0801349105

Zhang, Y., Ali, S. F., Dervishi, E., Xu, Y., Li, Z., Casciano, D., et al. (2010). Cytotoxicity effects of graphene and single-wall carbon nanotubes in neural phaeochromocytoma-derived PC12 cells. ACS Nano 4, 3181-3186. doi: $10.1021 / \mathrm{nn} 1007176$

Zhang, L., Xia, J., Zhao, Q., Liu, L., and Zhang, Z. (2010). Functional graphene oxide as a nanocarrier for controlled loading and targeted delivery of mixed anticancer drugs. Small 6, 537-544. doi: 10.1002/smll.200901680

Zhang, J., Ge, J., Shultz, M. D., Chung, E., Singh, G., Shu, C., et al. (2010c). In vitro and in vivo studies of single-walled carbon nanohorns with encapsulated metallofullerenes and exohedrally functionalized quantum dots. Nano Lett. 10, 2843-2848. doi: 10.1021/nl1008635

Zhang, X., Yin, J., Peng, C., Hu, W., Zhu, Z., Li, W., et al. (2011). Distribution and biocompatibility studies of graphene oxide in mice after intravenous administration. Carbon 49, 986-995. doi: 10.1016/j.carbon.2010.11.005

Zhang, Y., Xu, Y., Li, Z., Chen, T., Lantz, S. M., Howard, P. C., et al. (2011). Mechanistic toxicity evaluation of uncoated and PEGylated single-walled 
carbon nanotubes in neuronal PC12 cells. ACS Nano 5, 7020-7033. doi: $10.1021 / \mathrm{nn} 2016259$

Zhang, X.-Q., Lam, R., Xu, X., Chow, E. K., Kim, H.-J., and Ho, D. (2011). Multimodal nanodiamond drug delivery carriers for selective targeting, imaging, and enhanced chemotherapeutic efficacy. Adv. Mater. 23, 4770-4775. doi: 10.1002/adma.201102263

Zhang, H., Yu, M., Xie, L., Jin, L., and Yu, Z. (2012). Carbon-nanofibers-based micro-/nanodevices for neural-electrical and neural-chemical interfaces. J. Nanomater. 2012, 1-6. doi: 10.1155/2012/280902

Zhang, Y., Nayak, T. R., Hong, H., and Cai, W. (2012). Graphene: a versatile nanoplatform for biomedical applications. Nanoscale 4, 3833. doi: $10.1039 / \mathrm{c} 2 \mathrm{nr} 31040 \mathrm{f}$

Zhang, M., Zhou, X., Iijima, S., and Yudasaka, M. (2012). Small-sized carbon nanohorns enabling cellular uptake control. Small 8, 2524-2531. doi: 10.1002/smll.201102595

Zhang, H., Grüner, G., and Zhao, Y. (2013). Recent advancements of graphene in biomedicine. J. Mater. Chem. B 1, 2542. doi: 10.1039/c3tb20405g

Zhang, X., Wang, S., Liu, M., Yang, B., Feng, L., Ji, Y., et al. (2013). Size tunable fluorescent nano-graphite oxides: preparation and cell imaging applications. Phys. Chem. Chem. Phys. 15, 19013. doi: 10.1039/c3cp52883a

Zhang, J., and Yu, S. (in press). Carbon dots : large-scale synthesis, sensing and bioimaging. Biochem. Pharmacol. doi: 10.1016/j.mattod.2015.11.008

Zhao, Q.-L., Zhang, Z.-L., Huang, B.-H., Peng, J., Zhang, M., and Pang, D.-W. (2008). Facile preparation of low cytotoxicity fluorescent carbon nanocrystals by electrooxidation of graphite. Chem. Commun. 5116-5118. doi: 10.1039/b812420e

Zhao, D., Alizadeh, D., Zhang, L., Liu, W., Farrukh, O., Manuel, E., et al. (2011). Carbon nanotubes enhance cpg uptake and potentiate antiglioma immunity. Clin. Cancer Res. 17, 771-782. doi: 10.1158/1078-0432.CCR$10-2444$
Zhao, Q., Li, N., Shu, C., Li, R., Ma, X., Li, X., et al. (2015). Docetaxel-loaded single-wall carbon nanohorns using anti-VEGF antibody as a targeting agent: characterization, in vitro and in vivo antitumor activity. J. Nanoparticle Res. 17, 207. doi: 10.1007/s11051-015-3015-4

Zhao, A., Chen, Z., Zhao, C., Gao, N., Ren, J., and Qu, X. (2015). Recent advances in bioapplications of C-dots. Carbon 85, 309-327. doi: 10.1016/j.carbon.2014.12.045

Zhu, S., Oberdörster, E., and Haasch, M. L. (2006). Toxicity of an engineered nanoparticle (fullerene, C60) in two aquatic species, Daphnia and fathead minnow. Mar. Environ. Res. 62, S5-S9. doi: 10.1016/j.marenvres.2006. 04.059

Zhu, S., and Xu, G. (2010). Single-walled carbon nanohorns and their applications. Nanoscale 2, 2538. doi: 10.1039/c0nr00387e

Zhu, S., Tang, S., Zhang, J., and Yang, B. (2012). Control the size and surface chemistry of graphene for the rising fluorescent materials. Chem. Commun. 48, 4527. doi: 10.1039/c2cc31201h

Zhu, Y., Li, J., Li, W., Zhang, Y., Yang, X., Chen, N., et al. (2012). The biocompatibility of nanodiamonds and their application in drug delivery systems. Theranostics 2, 302-312. doi: 10.7150/thno.3627

Conflict of Interest Statement: The authors declare that the research was conducted in the absence of any commercial or financial relationships that could be construed as a potential conflict of interest.

Copyright (C) 2016 Baldrighi, Trusel, Tonini and Giordani. This is an open-access article distributed under the terms of the Creative Commons Attribution License (CC $B Y)$. The use, distribution or reproduction in other forums is permitted, provided the original author(s) or licensor are credited and that the original publication in this journal is cited, in accordance with accepted academic practice. No use, distribution or reproduction is permitted which does not comply with these terms. 